\title{
Influence of kaolin and coal fly ash addition on biomass ash deposition in an entrained
} flow reactor

Wang, Guoliang; Poulsen, Jesper Naimi Funch; Poulsen, Samira Naimi Funch; Jensen, Peter Arendt; Frandsen, Flemming Jappe

\section{Published in:}

Fuel

Link to article, DOI:

10.1016/j.fuel.2021.123041

Publication date:

2022

Document Version

Publisher's PDF, also known as Version of record

Link back to DTU Orbit

Citation (APA):

Wang, G., Poulsen, J. N. F., Poulsen, S. N. F., Jensen, P. A., \& Frandsen, F. J. (2022). Influence of kaolin and coal fly ash addition on biomass ash deposition in an entrained flow reactor. Fuel, 313, [123041]. https://doi.org/10.1016/j.fuel.2021.123041

\section{General rights}

Copyright and moral rights for the publications made accessible in the public portal are retained by the authors and/or other copyright owners and it is a condition of accessing publications that users recognise and abide by the legal requirements associated with these rights.

- Users may download and print one copy of any publication from the public portal for the purpose of private study or research.

- You may not further distribute the material or use it for any profit-making activity or commercial gain

- You may freely distribute the URL identifying the publication in the public portal 
Full Length Article

\title{
Influence of kaolin and coal fly ash addition on biomass ash deposition in an entrained flow reactor
}

\author{
Guoliang Wang *, Jesper Naimi Funch Poulsen, Samira Naimi Funch Poulsen, \\ Peter Arendt Jensen, Flemming Jappe Frandsen \\ Department of Chemical and Biochemical Engineering, Technical University of Denmark, Søltofts Plads, Building 229, DK-2800 Kgs. Lyngby, Denmark
}

\section{A R T I C L E I N F O}

\section{Keywords:}

Kaolin

Coal fly ash

Potassium capture

Biomass combustion

Alkali

\begin{abstract}
A B S T R A C T
The ash deposition behavior when firing different biomass (pulverized wheat straw, wood, bark, and leaves), with and without K-capture additives (kaolin and coal fly ash) was investigated through combustion experiments in the DTU (Technical University of Denmark) entrained flow reactor (EFR). In terms of deposit formation, the Kand Cl-rich Danish wheat straw proved to be the most problematic fuel, while milled wood pellets, leaves, and bark had significantly lower deposition propensities. Kaolin and two types of coal fly ash (Al- and Si-rich) were used as K-capture additives, and the results showed that with a fuel-K/additive-Al molar ratio of 1.0, the deposition propensity of wheat straw combustion was significantly reduced. However, the deposition propensity of the combustion of milled wood pellets did not change significantly with the addition of additives. ICPelemental analysis of the deposits and fly ash samples showed that the water-soluble K content in the deposits and fly ash was significantly reduced for both wheat straw and wood pellet combustion. In comparison with the data from previous experiments, where pure K-salt reacted with solid additives, kaolin captured $\mathrm{KOH}$ more effectively than real biomass combustion. For coal fly ash, an opposite tendency was observed, i.e., it captured $\mathrm{K}$ more effectively under real biomass combustion conditions than under pure $\mathrm{KOH}$ reaction conditions.
\end{abstract}

\section{Introduction}

Biomass energy utilization began in small (usually below $20 \mathrm{MW}_{\mathrm{th}}$ ) dedicated combined heat and power plants and was typically based on grate-firing or fluidized bed technology. Thermal processing of large amounts of straw or wood in such units requires many plants [1]. Additionally, some serious operational problems, such as slagging, fouling, and corrosion in grate-fired units and de-fluidization in fluidized bed combustion (FBC) units, have hampered the utilization of combustion-based biomass energy. Furthermore, the electrical efficiency in these units has traditionally been rather low, at approximately $30 \%$, compared to $45-48 \%$ in coal-fired power stations [1]. The shift to co-firing biomass with coal in large-capacity (up to $600 \mathrm{MW}_{\mathrm{th}}$ ) suspension-firing boilers has made it possible to process much larger amounts of biomass with a significantly increased electrical efficiency. The natural progress is the thermal processing of only the biomass without fossil fuel co-firing in suspension-firing units, which is referred to as biodust combustion. However, suspension-fired boilers that process biomass without any fossil fuel additive are vulnerable to issues regarding severe deposit formation, increased corrosion [1], and deactivation of de-NOx catalysts in the flue gas cleaning system [2,3]. All these issues are caused by the relatively high content of alkali metals in the biomass ash, which leads to a high content of salt species such as $\mathrm{KCl}$, $\mathrm{KOH}$, and $\mathrm{K}_{2} \mathrm{SO}_{4}$ in the flue gas. Therefore, additives that can fix the biomass fuel potassium in species while being less problematic for boiler operation are required.

Recently, much focus has been placed on testing different types of solid additives that can capture K-salts and thereby solve various ashrelated problems. Taking $\mathrm{KCl}$ as an example, the reaction occurs between the condensed-phase kaolin particle and gas-phase $\mathrm{KCl} ; \mathrm{Cl}$ is released as $\mathrm{HCl}$, and potassium is bound to alumina silicates that have a relatively high melting point. The commonly studied K-capture additives have recently been compared and summarized [4-9]. K-capture additives can generally be classified into three types on the basis of the active elements present in the additives: Al-Si-based, S-based, and P-Cabased. Kaolin and coal fly ash are two typical Al-Si-based additives, and have been extensively studied at the laboratory scale [10-12], pilotscale rigs [13-18], and full-scale boilers [5,19]. However, only few

\footnotetext{
* Corresponding author.

E-mail address: guow@kt.dtu.dk (G. Wang).
} 
quantitative studies on the effects of K-capture additives under suspension-fired conditions are publicly available. In our previous work using an entrained flow reactor (EFR), the K-capture reaction of kaolin and coal fly ash under suspension-fired conditions was quantitatively investigated using various pure $\mathrm{K}$-salts $\left(\mathrm{KOH}, \mathrm{KCl}, \mathrm{K}_{2} \mathrm{CO}_{3}\right.$, and $\left.\mathrm{K}_{2} \mathrm{SO}_{4}\right)$ [15-18]. The results showed that the K-capture reaction was influenced by the reaction temperature, type of salt, and ratio of K-salts to additives. In another study, biomass combustion with additive addition was carried out in a full-scale suspension-fired boiler $[5,19]$. Coal fly ash was injected during pulverized wood combustion, and deposit and aerosol formation were quantified using a low-pressure cascade impactor and an advanced deposit probe. The results revealed that the ash deposit became less troublesome with a less-sintered structure, when coal fly ash was added, which could easily be removed by natural shedding or soot blowing. The formation of aerosols significantly suppressed as well [20]. However, the amount of K-capture by the additives and the K-conversion level were not quantitatively studied in their work.

As mentioned above, K-capture reactions have been widely studied. However, to the best of our knowledge, very few quantitative studies or data on K-capture by solid additives under real biomass suspensionfiring conditions have been published. The objective of the present work is to quantitatively study the reaction between solid additives (kaolin and coal fly ash) and the volatile K-salt species, originating from biomass combustion, under well-controlled suspension-fired conditions. Furthermore, the deposit formation behavior, when firing different biomass, and the influence of additive addition on deposition, as well as aerosol formation, were investigated in detail.

The research activities of this work were conducted within the framework of the EU Horizon 2020 BIOFFICIENCY project, which aims to develop the next generation of highly efficient, low-emitting biomassbased boilers with increased steam temperatures up to $600{ }^{\circ} \mathrm{C}[21,22]$. In this project, whole-life-cycle ash-related problems have been investigated, including pretreatment of low-grade fuels, ash formation, use of additives, and biomass ash utilization.

\section{Experimental}

\subsection{Fuels and additives}

Four different types of pulverized biomass fuels were used in this

Table 1

Elemental composition of the ash in the fuels used in this work. Elemental composition of the fuels was analyzed by ICP-OES and recalculated into ashbasis.

\begin{tabular}{llcrr}
\hline Characteristics & $\begin{array}{l}\text { milled Danish } \\
\text { wheat straw }\end{array}$ & $\begin{array}{l}\text { milled } \\
\text { wood } \\
\text { pellets }\end{array}$ & $\begin{array}{l}\text { SE- } \\
\text { bark }\end{array}$ & $\begin{array}{l}\text { HTC- } \\
\text { leaves }\end{array}$ \\
\hline Si (wt. \% dry) & 25.1 & 8.9 & 9.1 & 13.7 \\
Al (wt. \% dry) & 0.1 & 1.4 & 2.0 & 2.0 \\
Ca (wt. \% dry) & 7.8 & 22.8 & 23.5 & 29.3 \\
Mg (wt. \% dry) & 1.4 & 4.0 & 1.6 & 2.7 \\
K (wt. \% dry) & 16.2 & 16.9 & 4.3 & 1.8 \\
Na (wt. \% dry) & 0.2 & 0.5 & 0.7 & 0.2 \\
Fe (wt. \% dry) & 0.2 & 1.1 & 0.9 & 3.6 \\
Ti (wt. \% dry) & NA* & 0.1 & 0.1 & 0.1 \\
Mn (wt. \% dry) & NA* & 0.6 & 1.4 & 0.1 \\
P (wt. \% dry) & 1.7 & 1.2 & 1.0 & 1.3 \\
S (wt. \% dry) & 2.0 & 0.6 & 0.6 & 0.5 \\
Cl (wt. \% dry) & 3.4 & 0.01 & 0.3 & 0.01 \\
O (wt. \% dry) & 41.8 & 42.3 & 54.7 & 45.1 \\
molar K/Al & 102.6 & 8.1 & 1.5 & 0.6 \\
molar K/Si & 0.5 & 1.4 & 0.3 & 0.1 \\
molar Cl/K & 0.2 & 0.0 & 0.1 & 0.0 \\
molar (K + Na)/(Cl & 1.92 & 12.04 & 3.06 & 1.74 \\
$\quad+$ 2S) & & & & \\
ash content in fuel & 5.6 & 1.1 & 4.6 & 13.9 \\
(wt. \% dry) & & & & \\
\hline
\end{tabular}

*Note: NA means data are not available. study, as listed in Table 1, including milled Danish wheat straw, milled wood pellets, steam exploded bark (SE-bark), and hydrothermal carbonation-treated leaves (HTC-leaves). The ash contents and the elemental composition of the ash in the fuels were analyzed and are listed in Table 1.

The milled wood pellet sample has the lowest ash content (1.1\%) among the four fuels, while the ash contents of SE-bark and milled Danish wheat straw are relatively high at $4.6 \%$ and $5.6 \%$, respectively. The HTC-leaves comparatively have the highest ash content (13.9\%). The elemental composition of the different fuel ashes shows that both SE-bark and HTC-leaves are rich in Si and Ca, while their K content is significantly lower than that of milled wood pellets and milled Danish wheat straw. The Al content of SE-bark and HTC-leaves is also higher than that of milled wood pellets and wheat straw. The difference indicates that SE-bark and HTC-leaves are expected to be less troublesome, from the viewpoint of ash-related problems. Because they have a low $\mathrm{K}$ content and low $\mathrm{K} / \mathrm{Si}$ and $\mathrm{K} / \mathrm{Al}$ molar ratios in the ash, which could indicate a high potential for binding the $\mathrm{K}$ in high melting point species.

The milled wood pellets and Danish wheat straw are generally rich in $\mathrm{K}, \mathrm{Si}$, and $\mathrm{Ca}$. However, one difference between the two fuels is that the milled wood pellets have a significantly less amount of $\mathrm{Cl}$ than milled wheat straw. Another difference is the much lower ash content in the milled wood pellets. The SE-bark and HTC-leaves used in this work have a much lower $\mathrm{K}$ content than wood pellets and wheat straw. Additionally, the Ca content is higher in SE-bark and HTC-leaves than in milled wheat straw.

The molar ratios of $\mathrm{K} / \mathrm{Al}, \mathrm{K} / \mathrm{Si}$, and $\mathrm{Cl} / \mathrm{K}$ of different fuels were calculated on the basis of the elemental composition of the fuels, as shown in Table 1 . The molar ratio of $\mathrm{K} / \mathrm{Al}$ in milled wheat straw is as high as 102.6, which means that potassium cannot be bound to Al-Sispecies without using additives.

One kaolin and two coal fly ashes (CFA-A and CFA-H) were used as the K-capture additives in this work. The elemental compositions and other properties of the three additives are listed in Table 2. As seen in the table, all three additives are rich in $\mathrm{Al}$ and $\mathrm{Si}$, and the molar ratio of $(\mathrm{K}+$ $\mathrm{Na}) /(\mathrm{Al}+\mathrm{Si})$ is below 0.05 for all additives, indicating that a large fraction of $\mathrm{Al}$ and $\mathrm{Si}$ is available for $\mathrm{K}$-capture reaction. One difference is that the Ca content in the two coal fly ashes is higher than that in kaolin, which may hinder the availability of $\mathrm{Al}$ and $\mathrm{Si}$ to some extent because $\mathrm{Ca}$ may compete with the biomass-K while reacting with $\mathrm{Al}$ and $\mathrm{Si}$. Another difference is that kaolin has a relatively higher $\mathrm{Al}$ content and molar $\mathrm{Al}$ / $\mathrm{Si}$ ratio (0.89) than those of the two coal fly ashes, whose molar Al/Si ratios are only 0.64 and 0.52 . A higher $\mathrm{Al} / \mathrm{Si}$ ratio may indicate a higher K-capture capability of kaolin. Among the two coal fly ashes, CFA-A has a lower $\mathrm{K}$ and $\mathrm{Ca}$ content and residual carbon content but a slightly higher $\mathrm{Al}$ content; therefore, a higher K-capture capability is expected

Table 2

Elemental composition of the three K-capture additives: kaolin and two coal fly ashes (The elemental composition was analyzed by ICP-OES).

\begin{tabular}{lccc}
\hline Characteristics & kaolin & CFA-A $^{\mathbf{a}}$ & CFA-H $^{\mathbf{b}}$ \\
\hline Si (wt. \% dry) & 23.33 & 25.38 & 24.17 \\
Al (wt. \% dry) & 19.99 & 15.72 & 12.13 \\
Ca (wt. \% dry) & 0.04 & 3.77 & 4.26 \\
Mg (wt. \% dry) & 0.21 & 0.70 & 1.05 \\
K (wt. \% dry) & 1.88 & 1.00 & 1.48 \\
Na (wt. \% dry) & 0.05 & 0.31 & 0.59 \\
Fe (wt. \% dry) & 0.69 & 2.59 & 4.10 \\
Ti (wt. \% dry) & 0.06 & 0.89 & 0.65 \\
P (wt. \% dry) & 0.04 & 0.57 & 0.50 \\
S (wt. \% dry) & $<0.01$ & 0.31 & 0.39 \\
C (wt. \% dry) & $<0.1$ & 0.60 & 6.00 \\
O (calculated) & 53.71 & 48.15 & 44.68 \\
Molar (K + Na)/(Al + Si) & 0.03 & 0.03 & 0.05 \\
molar Al/Si & 0.89 & 0.64 & 0.52 \\
\hline
\end{tabular}

a. CFA-A stands for coal fly ash - A;

b. CFA-H stands for coal fly ash $-\mathrm{H}$. 
for CFA-A.

\subsection{Setup}

Experiments were conducted in the DTU EFR, consisting of a gas supply system, screw feeder for injecting solids (fuels and additives), gas preheater, $2 \mathrm{~m}$ long electrically heated furnace tube, fly ash deposition system, and solid sample sampling system (a cyclone and a metal filter). Schematic representations of the EFR reactor and the deposit probe are shown in Fig. 1 and Fig. 2, respectively. More details on the EFR and fly ash deposition system can be found in our previous work [13,23,24].

Fuels and additives were premixed well and added to the screw feeder. The mixing continued in the feeding chamber of the screw feeder. The fuel-additive mixture was then transported by the primary air through a water-cooling feeding probe into the furnace tube. The secondary air was simultaneously preheated by the preheater and came in contact with the primary air at the entrance of the furnace tube, where the fuels burned. Thereafter, fuel combustion, ash formation, volatile alkali species release into the gas phase, and reaction with the additives occurred in the high-temperature furnace tube.

After combustion and reaction in the furnace tube, the biomass ash and additive particles were entrained by flue gas to a water-cooled bottom chamber, where the ash particles collide with the air-cooled deposit probe. A deposit was formed on the steel tube (type 316), simulating the deposit formation process on the leading edge of the plate super heater tubes in boilers. The steel tube, with an outer diameter of $10 \mathrm{~mm}$, thickness of $1 \mathrm{~mm}$, and length of $140 \mathrm{~mm}$, was mounted on a retractable annular-cooled probe (diameter of $8 \mathrm{~mm}$ ), as shown in Fig. 2.

The deposition probe was cooled using air, whose flow rate was

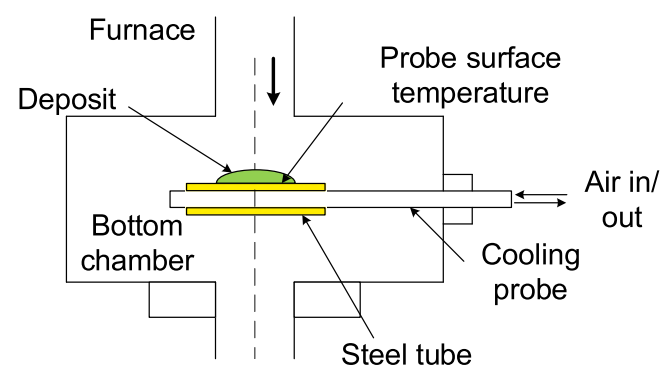

Fig. 2. Air-cooled deposit probe mounted inside the bottom chamber of the EFR. Deposits are formed on the steel tube mounted on the probe [23].

regulated by a PID (proportional-integral-derivative) control system. To obtain an even temperature distribution throughout the steel tube, the cooling air was preheated to $200{ }^{\circ} \mathrm{C}$ before being sent to the deposit probe. Thermocouples were embedded on the outer surface of the deposit probe (and thereby, in contact with the inner surface of the steel tube), and the temperature at the axial centerline of the reactor (referred to as probe surface temperature, see Fig. 2) was employed as a feedback for the cooling air PID control system. The fly ash deposition process was continuously recorded using a video camera mounted on the port of the bottom chamber (see Fig. 2). After deposit formation for a specified duration, the deposit probe was retracted, and the deposit was removed, weighed, and collected for further analysis.

A part of the fly ash was entrained with the flue gas into the sampling probe and subsequently collected by the cyclone and metal filter. Fly ash was also observed on the inner wall of the water-cooled bottom chamber

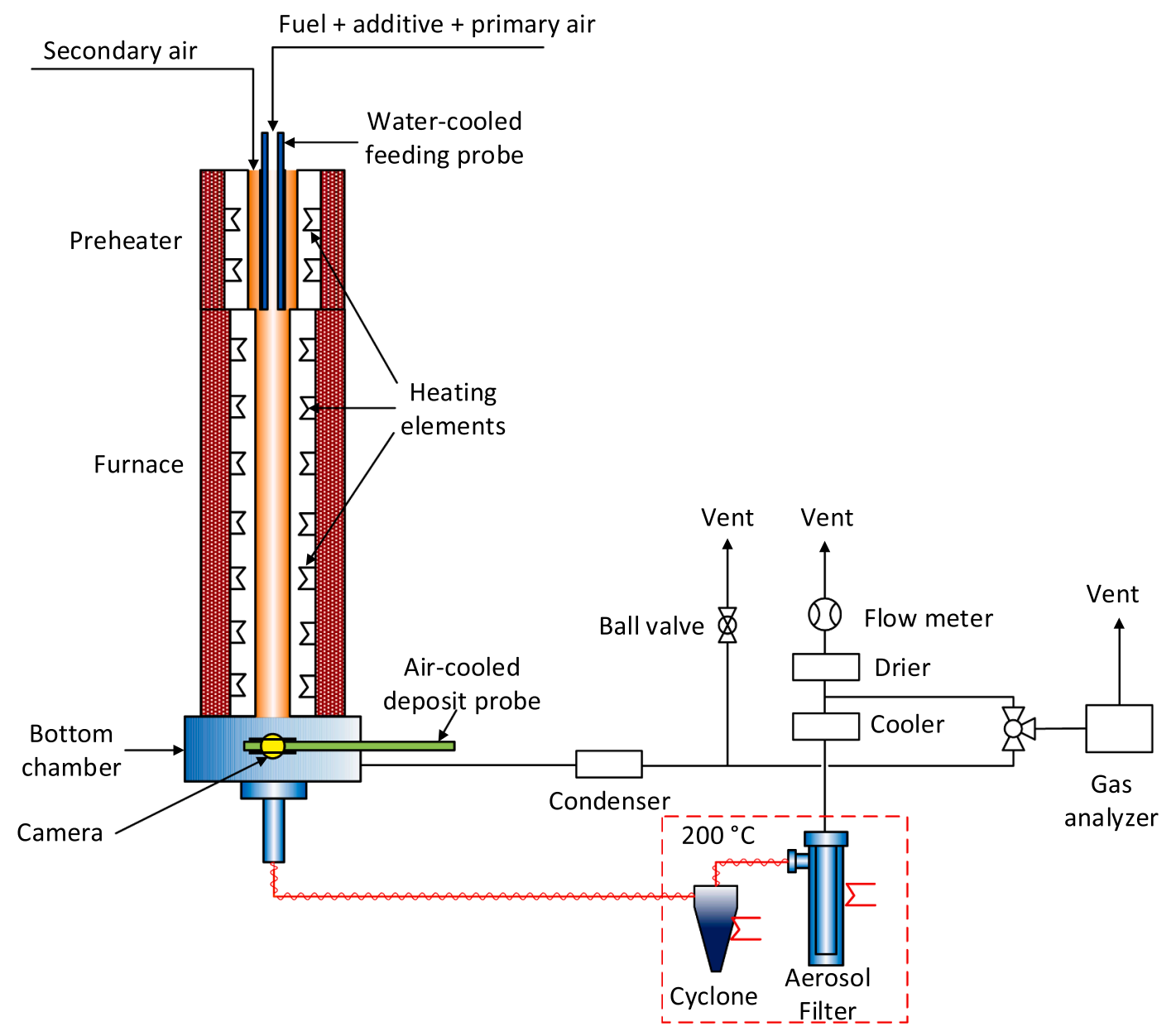

Fig. 1. Schematic drawing of the DTU entrained flow reactor (EFR). 
and the tubes connecting the sampling probe, cyclone, and filter. To collect as much fly ash as possible and thoroughly clean the sample tube, high-pressure air was used to flush the entire sample system of the EFR after each experiment.

The sampling probe, cyclone, and metal filter were all heated to $200{ }^{\circ} \mathrm{C}$ to avoid water condensation. Bigger ash particles were collected in the cyclone, whereas aerosols were captured by the metal filter. The cyclone ash particles and aerosols were carefully collected and weighed for further analysis.

\subsection{Experimental matrix}

In all experiments, the preheater and furnace temperatures of the EFR were set to $1100{ }^{\circ} \mathrm{C}$ and $1350{ }^{\circ} \mathrm{C}$, respectively. The surface temperature of the deposit probe was maintained at $600{ }^{\circ} \mathrm{C}$. An identical excess air ratio $\lambda=1.3$ and a flue gas residence time of $2.0 \mathrm{~s}$ were applied in all experiments. Therefore, a gas velocity of $1.0 \mathrm{~m} / \mathrm{s}$ was achieved in all experiments.

Two types of experiments were conducted in this work: combustion experiments without additives (No. 1-4 in Table 3) and additive experiments with K-capture additive injected together with the fuels (No. 5-12 in Table 3).

Four different fuels were used in the combustion experiments: milled Danish wheat straw, pulverized wood pellets, SE-bark, and HTC-leaves (see experiments 1-4 in Table 3). The ash contents of the four fuels varied significantly. To achieve a comparable cumulative ash feeding amount, the run time of the combustion experiments without additive addition (No. 1-4 in Table 3) was varied from $20 \mathrm{~min}$ to $180 \mathrm{~min}$.

To study the influence of additives on deposit formation and fly ash properties, additive experiments were conducted. However, only wheat straw and milled wood pellets were used for the additive addition experiments (see Experiment Nos. 5-12 in Table 3). The low K/Al and K/Si molar ratios of the fuel ash for SE-bark and HTC-leaves made it less relevant to use additives with those fuels. In particular, the relatively high amounts of $\mathrm{Al}$ and $\mathrm{Si}$ in the HTC-leaves were sufficient for capturing the fuel K. For Experiment Nos. 5-12, the additive dosage was calculated, assuming that the K-species from the fuel reacted individually with the $\mathrm{Al}$ and $\mathrm{Si}$ from the additive, forming $\mathrm{K}$-aluminosilicate. Because $\mathrm{Si}$ is readily available in both fuels and additives, it is assumed to be of limited importance. Therefore, as shown in Table 3, all experiments involving additive addition, except for Experiment No. 8, were conducted with a molar fuel-K/additive-Al ratio of 1.0. Experiment No. 8 (wheat straw with kaolin addition) was conducted with a double dosage of kaolin, i.e., with a fuel-K/additive-Al molar ratio of 0.5. The aim of this experiment was to study the influence of higher additive dosages on deposit formation and ash properties. In order to check the experimental reproducibility, Experiment Nos. 5 and 9 (wheat straw with kaolin addition) were conducted under the same conditions.

\section{Methods of analyzing and quantifications}

\subsection{Deposition propensity}

In order to compare the extent to which the fly ash particles adhere to the surface of the deposit probe when firing the different fuels and the influence of additive addition, the deposition propensity $\left(D_{p}\right)$ was calculated as the ratio between the measured deposit buildup and the theoretically estimated maximum deposit buildup. The maximum possible deposit buildup would occur if all incoming ash particles in the probe area collide with and adhere to the probe. The deposit propensity is defined using Eq. (1).

$D_{p}=\frac{m_{m s d}}{m_{t h}} \times 100 \%$

where $\mathrm{m}_{\mathrm{msd}}$ is the mass of the ash deposit measured or collected from the deposit probe, while $\mathrm{m}_{\mathrm{th}}$ is the mass of ash deposit that could theoretically build up on the deposit probe, assuming that all ash particles flowing throughout the area of the probe would collide with the probe and adhere to it. By using the deposit propensity, it is possible to compare the influence of the ash chemistry of different fuels on the deposit formation process, even when the fuels have different ash contents. The maximum theoretical ash deposit buildup can be calculated using Eq. (2).

$m_{\text {th }}=m_{\text {feed }} \frac{A_{\text {probe }}}{A_{\text {tube }}}$

where $\mathrm{m}_{\text {feed }}$ is the total feeding amount of fuel ash and additive, while Aprobe and $\mathrm{A}_{\text {tube }}$ are the projected area of the deposit probe and

Table 3

Experimental matrix conducted in the EFR (all experiments were conducted with a furnace temperature of $1350^{\circ} \mathrm{C}$ and a constant excess air ratio $\lambda=1.3$. Gas velocity was $1.0 \mathrm{~m} / \mathrm{s})$.

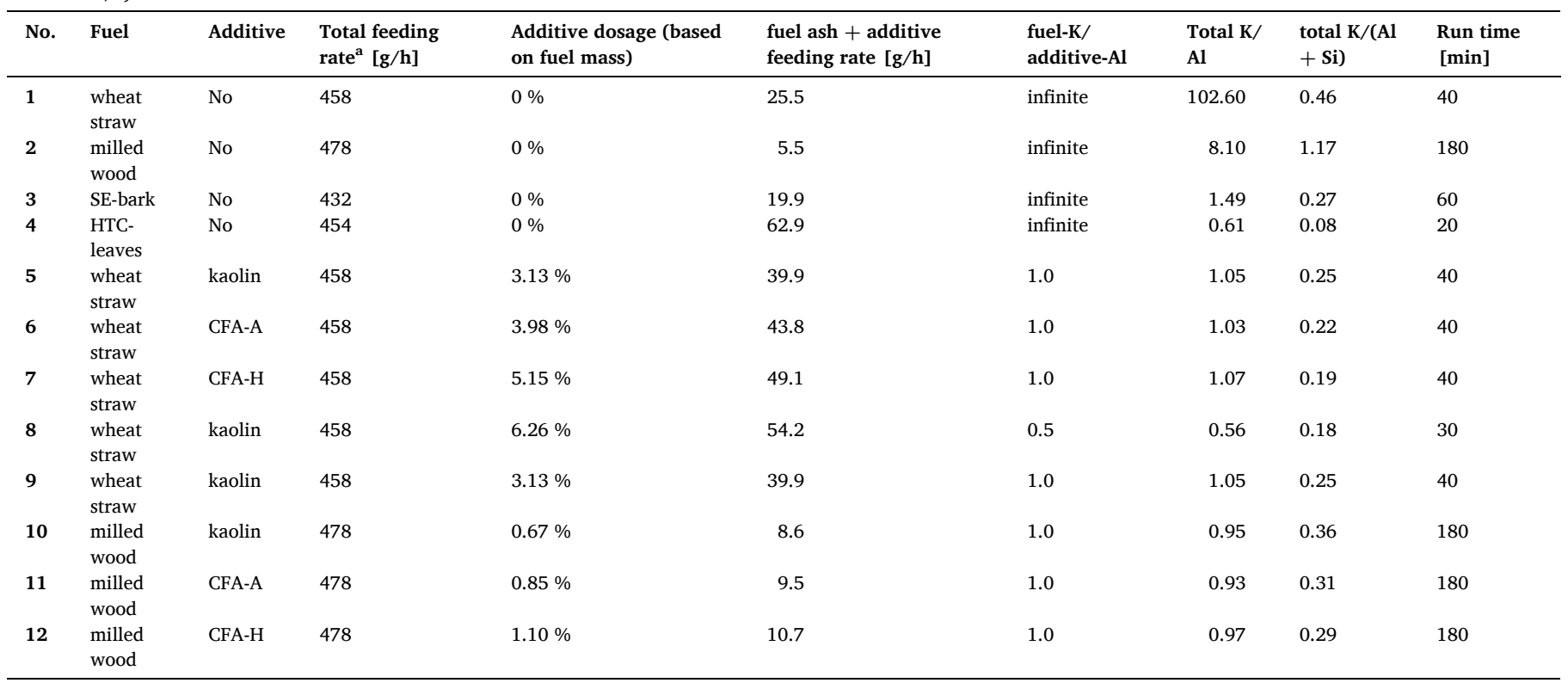

a. The total feeding rate include the fuel and additive. 
the inner area of the furnace tube, respectively, as shown in Fig. 3.

\subsubsection{Analytical methods}

Different characterization techniques have been employed in this work to obtain information on the deposits and fly ash. The bulk elemental composition of the samples, particularly the content of total $\mathrm{K}$ and water-soluble $\mathrm{K}$, was obtained by ICP-OES (Inductively coupled plasma atomic emission spectroscopy), which was conducted in accordance with the Danish Standards DS/EN ISO 16,995 (solid biofuels determination of the water-soluble $\mathrm{Cl}, \mathrm{Na}$ and $\mathrm{K}$ ) and DS/EN ISO 16,967 (solid biofuels - determination of major elements - Al, Ca, Fe, $\mathrm{Mg}, \mathrm{P}$, $\mathrm{K}, \mathrm{Si}, \mathrm{Na}$ and $\mathrm{Ti}$ ). For the total content of $\mathrm{Al}, \mathrm{Si}, \mathrm{Ca}$, and $\mathrm{K}, 50 \mathrm{mg}$ solid samples were mixed with $\mathrm{H}_{2} \mathrm{O}_{2}, \mathrm{HNO}_{3}$, and $\mathrm{HF}$. The mixture was then digested in a microwave oven at $210{ }^{\circ} \mathrm{C}$. After cooling, the solution was neutralized with $4.0 \%$ boric acid in a microwave oven at $180{ }^{\circ} \mathrm{C}$. The solution was then diluted to $100 \mathrm{ml}$ for ICP-OES. For the water-soluble $\mathrm{K}$ content, $20 \mathrm{mg}$ of the solid sample was added to $40 \mathrm{ml}$ ultrapure water, and the mixture was placed in a microwave oven at $120^{\circ} \mathrm{C}$ for $1 \mathrm{~h}$. After cooling, the mixture was filtered through a $0.45 \mu \mathrm{m}$ filter, and the liquid part was analyzed by ICP-OES. The analysis was conducted using SPECTRO Arcos FHS 12 instrument at Force Technology A/S in Denmark.

ICP-OES provided information on the elemental bulk composition of the ash samples but no information on the chemical association of elements in the sample. For chemical speciation, X-ray diffraction (XRD) was used to determine the crystalline phases in the samples. In this work, the XRD spectra of the ash and deposit samples were obtained using a Huber diffractometer with characteristic $\mathrm{Cu} \mathrm{K \alpha}$ radiation and operating conditions of $40 \mathrm{kV}$ and $40 \mathrm{~mA}$. The X-ray wavelength was $1.54056 \AA$. The identification of the main crystalline phase was performed using the JADE 6.0 software package (MDI Livermore, CA) and the diffraction database of PDF2-2004. However, owing to the complex composition and uncertainty of the possible components, it is almost impossible to obtain reliable quantitative data on different crystal compounds for the samples in this study. Therefore, only qualitative XRD results were included in this work, and the evolution of K-species in the K-capture reactions could not be investigated.

\subsubsection{K-capture Quantification}

To compare the K-capture abilities of kaolin and coal fly ash, two parameters were defined, similar to those applied in our previous work $[15,16]$ : K-conversion $\left(\mathrm{X}_{\mathrm{K}}, \%\right)$ and $\mathrm{K}$-capture $\left(\mathrm{C}_{\mathrm{K}}, \mathrm{g} \mathrm{K} / \mathrm{g}\right.$ additive). $\mathrm{K}$ conversion $\left(\mathrm{X}_{\mathrm{K}}\right)$ is the percentage of water-soluble fuel $\mathrm{K}$, which is captured by a solid additive and transferred into water-insoluble compounds. K-capture $\left(\mathrm{C}_{\mathrm{K}}\right)$ is the mass of fuel $\mathrm{K}$ captured by $1 \mathrm{~g}$ of solid additive. The calculation method for the two parameters is explained below.

As shown in Fig. 4, $\mathrm{K}$ originates from both the fuel and additives (kaolin or coal fly ash). The majority of $\mathrm{K}$ in the reactants was from the

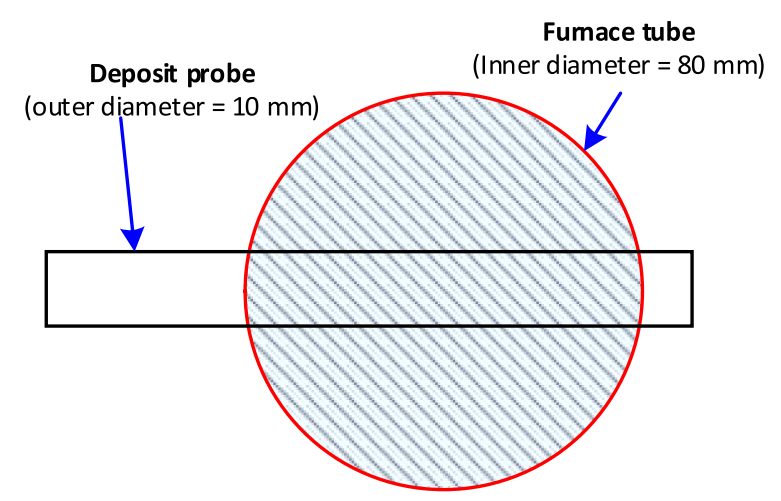

Fig. 3. Relation between the projected area of the deposit probe and the inner area of the furnace tube.

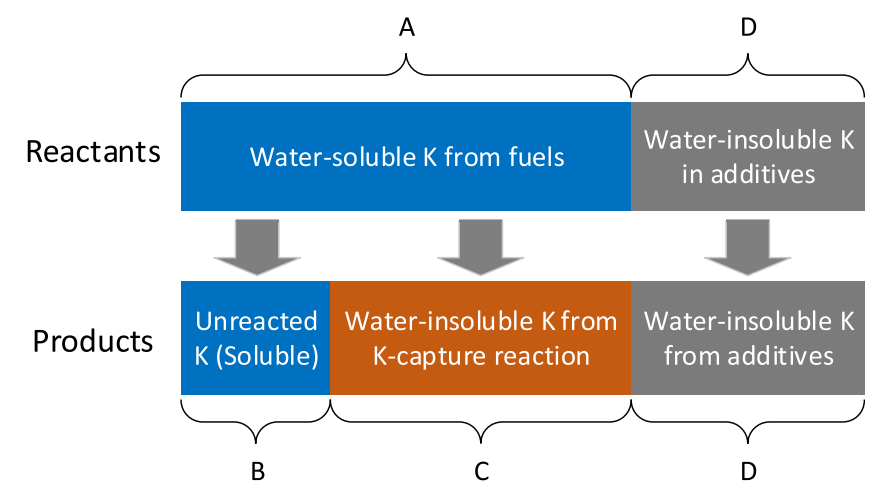

Fig. 4. Potassium transformations during the K-capture reaction [15]. The products refer to the fly ash samples collected from cyclone and filter.

fuels, which was assumed to be water-soluble (part A). The remaining $\mathrm{K}$ was obtained from the additives and was water-insoluble (part D). During the K-capture reaction, some of the water-soluble $\mathrm{K}$ reacted with additives to form water-insoluble $\mathrm{K}$-aluminosilicates (part $\mathrm{C}$ in the products), while the unreacted fuel $\mathrm{K}$-species remained water-soluble (part B). The K-conversion $\left(\mathrm{X}_{\mathrm{K}}\right)$ and K-capture level $\left(\mathrm{C}_{\mathrm{K}}\right)$ were calculated on the basis of the elemental composition of the input reactants and the ICP-OES data of the reacted products (the total and the watersoluble parts), as shown in Eq. (3-4). Detailed information on the calculation method can be found in our previous work $[14,15]$.

$X_{K}=\frac{C}{A} \times 100 \%$

$\mathrm{C}_{K}=\frac{n_{K-\text { fuel }} M_{K} X_{K}}{m_{a d}}$

where $\mathrm{C}$ is the amount of water-insoluble $\mathrm{K}$ formed by the K-capture reaction and $\mathrm{A}$ is the amount of $\mathrm{K}$ from the fuel fed into the reactor, as shown in Fig. 4. $\mathrm{n}_{\mathrm{K} \text {-fuel }}$ is the molar amount of water-soluble $\mathrm{K}$ in the reactants (mol). $M_{K}$ is the molar mass of potassium $(\mathrm{g} / \mathrm{mol}) . \mathrm{m}_{\mathrm{ad}}$ is the mass of the additives (kaolin or coal fly ash) in the reactants ( $g$ ). It is worth noting that simple additive dilution does not change the values of $\mathrm{X}_{\mathrm{K}}$ and $\mathrm{C}_{\mathrm{K}}$.

\section{Results and discussion}

\subsection{Experimental reproducibility}

As listed in the experimental matrix (Table 3), Experiment Nos. 5 and 9 were conducted under the same conditions to check the reproducibility of the experimental methodology. Some of the results from the two experiments are compared in Table 4. A more detailed comparison is shown in Table 7.

From Table 4, it is seen that the deposit propensity, K-conversion, and $\mathrm{K}$-capture level data vary by $0.1 \%, 7.4 \%$, and $0.02 \mathrm{~g} \mathrm{~K} /(\mathrm{g}$ additive) between Experiment Nos. 5 and 9, respectively. Therefore, the experiment is reasonably reproducible. From Table 7, it is observed that the chemical compositions of the collected deposits and fly ashes are reasonably similar for Experiment Nos. 5 and 9.

In all experiments, approximately $75 \%$ of the ash input is collected,

\section{Table 4}

Experimental reproducibility checking results (Conditions: wheat straw +3.13 $\%$ kaolin, feeding rate $=458 \mathrm{~g} / \mathrm{h}$, experiment time $=40 \mathrm{~min}$ ).

\begin{tabular}{lll}
\hline & Experiment No. 5 & Experiment No. 9 \\
\hline Deposition propensity (\%) & 28.8 & 28.9 \\
K-Conversion (\%)* & 68.6 & 61.2 \\
K-Capture level (g K/(g additive)) & 0.20 & 0.18 \\
\hline
\end{tabular}

*K-conversion is the fraction of $\mathrm{K}$ bound to the water-insoluble species. 
which may be considered to be unbalanced. However, owing to the complexity and size of the experimental setup, it is difficult to reach 100 $\%$ because some ash material is lost in the reactor walls. We calculated the $\mathrm{K} /(\mathrm{Al}+\mathrm{Si})$ ratio in the feed and products, and there is reasonable agreement. This indicates that the fraction of lost ash is similar to that of the collected samples.

\subsection{Deposition and ash properties when firing different fuels}

The ash formation and deposition behaviors, when firing different fuels without solid additives, was studied in three aspects: deposit morphology, deposition propensity, and deposit and fly ash chemistry.

\subsubsection{Deposit morphology}

Photographs of the deposit probe were taken after each experiment. The photographs of the probe deposits from the four fuels as seen from a side view are compared in Fig. 5. As described in Section 2.3, the run time of the four experiments was varied from 20 to $180 \mathrm{~min}$, to achieve a comparable cumulative ash feeding. The flue gas direction is marked in the figure as a white arrow.

As the photographs show, the largest amount of deposit is formed in the wheat straw combustion experiment (see Fig. 5 (A)). A distinct white K-salt layer is observed on the side surfaces of the deposit probe. The white salt layer was likely formed partly by the condensation of K-salt vapor, which was generated during the K-rich wheat straw combustion. Additionally, eddy diffusion and thermophoresis of submicron particles may also have contributed to the formation of the white deposit layer. The larger amount of deposit seen on the upstream side of the probe is formed by initial impaction [25]. When collecting the ash samples from the deposit probe, the ash deposit was quite compact, and only the uppermost layer of the deposit fell off easily. There is a second black layer beneath the loose deposit, which had to be physically knocked off. Finally, mostly a white layer was encountered at the bottom, similar to that observed on the side surface, which had to be brushed off with force.

For the milled wood combustion experiment, Fig. 5(B), a much thinner K-salt layer is observed, compared to that formed during wheat straw combustion. However, three distinct deposit layers were similarly observed while collecting the deposit. Firstly, a deposit is formed on the upstream/top side of the deposit probe; its quantity, however, is very small. The buildup can be easily removed by knocking the probe against a solid object, and thus shaking off the buildup. Secondly, an apparently centered, i.e., between the outermost deposit buildup and the innermost layer, beige colored layer is formed. This layer was more solid and had to be removed by brushing. Finally, a thin white layer is formed just below the middle beige layer. This innermost layer had to be brushed off with a stronger force, as it is quite sintered.

In the SE-bark combustion experiment, Fig. 5(C), similar to the milled wood combustion experiment, only a limited amount of deposit is formed on the probe, constituting a thin outer black deposit layer and an even thinner brown layer beneath. The outer black deposit sits on the upstream/top side of the probe and has a very loose structure. This outer layer deposit can be easily removed by turning the probe upside down. The thin brown layer beneath was relatively sintered, but less sintered compared to the innermost layer formed from wheat straw and milled wood combustion. This layer had to be removed by brushing. However, less force was required to brush it off compared to wheat straw and wood deposits.

A deposit with a similar structure is observed in the HTC-leaves combustion experiment Fig. 5 (D): a thin, loose deposit layer on top, which can be removed by simply turning the probe upside down, and an inner brown/beige sintered layer, which required physical brushing for its removal.

\subsubsection{Deposition propensity}

In this work, the deposition propensity of the four studied fuels, without additive addition, was calculated according to Eq. (1), and the results are compared in Fig. 6.

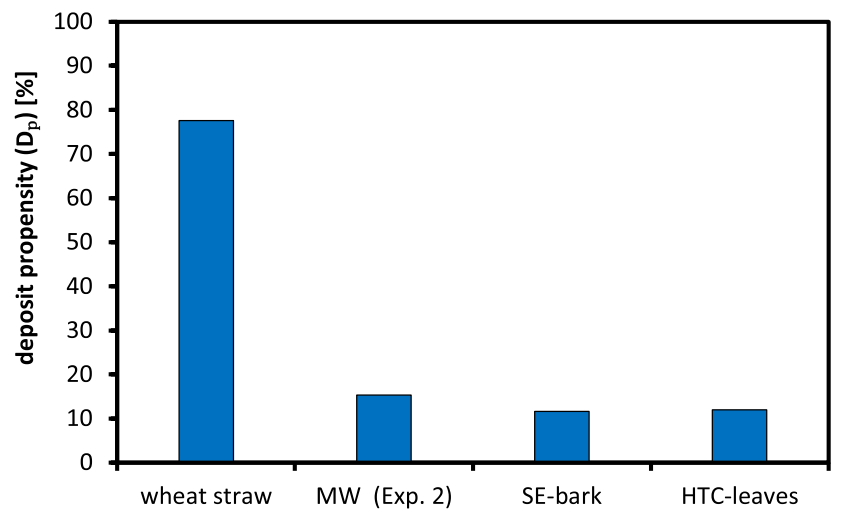

Fig. 6. Deposition propensity of wheat straw, milled wood, SE-bark, and HTC-leaves.

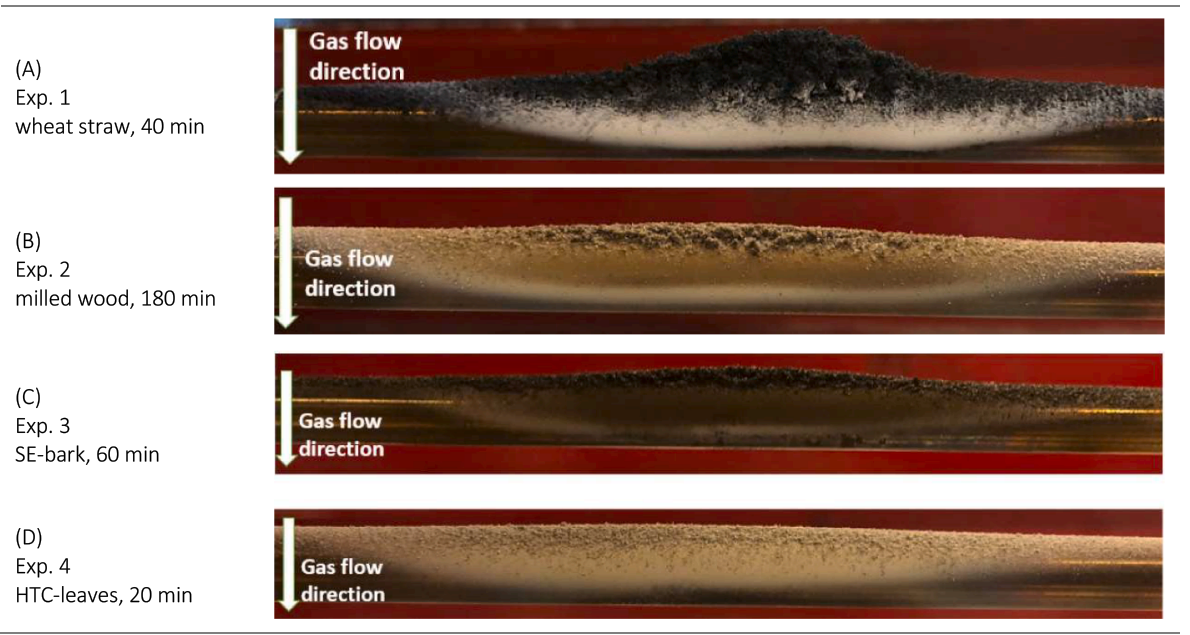

Fig. 5. Photographs of the deposits formed in combustion experiments without additive addition. Four fuels were fired: wheat straw, milled wood, SE-bark, and HTCleaves. For all experiments, the furnace temperature was $1350{ }^{\circ} \mathrm{C}$, residence time was $2.0 \mathrm{~s}$, excess air ration $\lambda=1.3$, and deposit probe surface temperature was $600{ }^{\circ} \mathrm{C}$. To achieve a comparative total ash feeding, the experiment run time was varied from $20 \mathrm{~min}$ to $180 \mathrm{~min}$. 
As shown in Fig. 6, wheat straw has the highest deposition propensity (77.5\%), indicating that $77.5 \%$ of the fly ash that collides with the deposit probe gets attached to the probe when firing wheat straw. The other three Ca-rich fuels, HTC-leaves, SE-bark, and milled wood, show significantly lower deposition propensity, varying from $11.6 \%$ to $15.3 \%$. The results show that the deposition propensity is highly related to the ash composition of the fuel feedstock.

\subsubsection{Deposit and fly ash chemistry}

The elemental compositions of the deposits (samples collected on the deposit probe) and fly ash (samples collected in the cyclone and filter), obtained by ICP-OES, are summarized in Table 5. The concentrations of $\mathrm{K}, \mathrm{Cl}, \mathrm{Al}, \mathrm{Si}$, and $\mathrm{Ca}$ and the concentrations of water-soluble $\mathrm{K}$ and $\mathrm{Ca}$ were analyzed. The "aerosol fraction" in Table 5 was calculated as the ratio between the mass of the filter sample and the mass of total ash samples, including deposit, cyclone ash, and filter ash. The K-conversion is the percentage of water-soluble $\mathrm{K}$ from the fuel feedstock that is transferred into water-insoluble K-compounds (Eq. (3)), which is due to the reaction between fuel-K and fuel-Al-Si. Other information, such as the molar ratio of fuel-K/fuel-Al and molar ratio of fuel-K/(fuel-Al + fuel-Si), was calculated on the basis of the elemental composition of the fuel feedstock and is included here for an easier overview.

The fuel ash elemental composition and fly ash composition (Table 5) infer that for wheat straw, both the fuel and the fly ash contain the highest elemental concentrations of $\mathrm{K}, \mathrm{Cl}$, and $\mathrm{Si}$ relative to the other fuels. These three elements can form $\mathrm{KCl}$ and $\mathrm{K}$-silicate with relatively low melting points. The $\mathrm{KCl}$ forms deposits by condensation, while the sticky K-silicate particles contribute to deposit formation by impaction [25].

Some binding of $\mathrm{K}$ in the water-insoluble chemical species in the fly ash is observed (high K-conversion) for SE-bark and HTC-leaves, which have a low molar ratio of $\mathrm{K} /(\mathrm{Al}+\mathrm{Si})$ in the fuels. The water-insoluble $\mathrm{K}$ in the fly ash products originates from the reactions of $\mathrm{K}$ with $\mathrm{Al}$ and $\mathrm{Si}$, both of which originate from the fuel feedstock. This is particularly true for HTC-leaves, with a molar ratio of $\mathrm{K} /(\mathrm{Al}+\mathrm{Si})$ as low as 0.08 and a 70 $\%$ binding of $\mathrm{K}$ in the water-insoluble species. For $\mathrm{Ca}$, fly ash from milled wood, SE-bark, and HTC-leaves have a larger Ca content of $21-31 \mathrm{wt} \%$, compared to only $7.4 \%$ in wheat straw.

In Table 6, XRD analysis provides information on the species distribution in different crystal phases of fly ash and deposits. The XRD analysis of the wheat straw fly ash samples reveals that the cyclone ash particles mainly consist of $\mathrm{KCl}, \mathrm{SiO}_{2}$, and $\mathrm{CaO}$. The filter aerosols from wheat straw combustion are comparatively dominated by $\mathrm{KCl}$, which is accompanied by a small amount of $\mathrm{K}_{2} \mathrm{SO}_{4}$ (with very weak peaks in the spectrum). The filter aerosols from all four fuel combustion experiments without additive addition contain $\mathrm{KCl}$, while for the milled wood, SE- bark and HTC-leaves, the aerosol filter samples contain $\mathrm{CaO}$ as well. The XRD data also show that $\mathrm{SiO}_{2}, \mathrm{CaO}$, and other $\mathrm{Ca}-\mathrm{Al}$ silicates are the dominant compounds in the cyclone samples. These species generally have relatively higher melting points and tend to form coarser particles, which are usually caught by the cyclone.

The deposit bottom (innermost layer of deposit) from wheat straw combustion is composed of $\mathrm{KCl}$ and $\mathrm{K}_{2} \mathrm{SO}_{4}$, which is probably mainly formed via heterogeneous condensation. $\mathrm{SiO}_{2}$ is also observed in the top samples of loose deposits. This is because inertial impaction is the dominant formation mechanism, thereby the larger ash particles containing $\mathrm{SiO}_{2}$ are captured by the sticky ash surface. For the other three fuels, the collected deposit samples are dominated by crystalline $\mathrm{SiO}_{2}$ and $\mathrm{CaO}$. The differences are mainly due to the differences in the ash elemental composition of the feedstock.

Comparing the chemical compositions of the fly ash and the deposits of the different fuels, the deposits contain less $\mathrm{K}, \mathrm{Ca}$, and $\mathrm{Cl}$ but more $\mathrm{Si}$ than the fly ash. This may be caused by the relatively high deposit probe temperature applied in this study $\left(600{ }^{\circ} \mathrm{C}\right)$, which may inhibit the condensation of gas-phase salt species but provide ideal conditions for capturing larger molten Si-rich particles. For the three Ca-rich fuels, Casilicate and $\mathrm{CaO}$ are observed in the fly ash and deposits, which have much higher melting points than the amorphous K-silicate. Amorphous $\mathrm{K}$-silicate is probably the main species in the wheat straw fly ash, and this explains why the Ca-rich fuels have a much smaller deposition propensity.

In summary, the ash elemental composition of the fuel feedstock plays a key role in the deposit formation process. A fuel rich in Si and $\mathrm{Al}$ relative to $\mathrm{K}$ (e.g., HTC-leaves) can form high-temperature melting Kspecies. In the case of the deposit probe temperature of $600{ }^{\circ} \mathrm{C}$, salt condensation seems to play a smaller role in the deposit formation process than at lower probe temperatures $[1,23]$, while K-silicate causes severe deposit formation. Increased fly ash Ca content decreases the fraction of melted particles, thereby reducing the deposition propensity.

\subsection{Impact of additive addition on deposit formation}

\subsubsection{Deposit morphology with additive addition}

Photographs of the probe deposits of all experiments with additive addition (experiment No. 5-12), are shown in Fig. 7. For deposits collected from wheat straw combustion, with $3.13 \%$ kaolin addition (Fig. 7 (A) and (E)), the main body of the deposit has a porous structure. Additionally, a white layer is formed on the side surfaces of the deposit probe. The white layer therein is much less distinct than that formed when firing wheat straw with no additives (i.e., Fig. 5(A)). The observed white material is possibly K-salts. Therefore, a reduction in the K-salt layer on the probe visually indicates the additive effect of reducing K-

Table 5

Elemental composition of the deposits and fly ashes in the experiments involving firing different fuels without additive addition. K-conversion values were calculated on the basis of fly ash samples (cyclone and filer sample).

\begin{tabular}{|c|c|c|c|c|c|c|c|c|}
\hline \multirow{3}{*}{$\begin{array}{l}\text { Experiment No. } \\
\text { Fuels }\end{array}$} & \multirow{2}{*}{\multicolumn{2}{|c|}{$\frac{1}{\text { wheat straw (WS) }}$}} & \multirow{2}{*}{\multicolumn{2}{|c|}{$\frac{2}{\text { milled wood (WP) }}$}} & \multirow{2}{*}{\multicolumn{2}{|c|}{$\frac{3}{\text { SE-Bark }}$}} & \multirow{2}{*}{\multicolumn{2}{|c|}{$\frac{4}{\text { HTC-leaves }}$}} \\
\hline & & & & & & & & \\
\hline & Fly ash & Dep. & Fly ash & Dep. & Fly ash & Dep. & Fly ash & Dep. \\
\hline K (water-soluble) [\%] & 8.5 & 3.9 & 8.4 & 2.8 & 3.2 & 0.79 & 0.58 & 0.21 \\
\hline Ca (water-soluble) [\%] & NA & NA & NA & NA & 14 & 7.8 & 9.2 & 6.9 \\
\hline K (total) [\%] & 12.4 & 8.2 & 9.8 & 5.1 & 4.3 & 2.6 & 1.9 & 1 \\
\hline $\mathrm{Cl}$ (total) [\%] & 5.9 & 1.6 & 1.6 & 0.5 & 0.7 & 0.5 & 0.5 & 0.5 \\
\hline Ca (total) [\%] & 7.4 & 2.9 & 21 & 15.3 & 33 & 27 & 31 & 22 \\
\hline Al (total) [\%] & 1.1 & 0.14 & 1.9 & 2.2 & 2.4 & 3.2 & 2.9 & 2 \\
\hline Si (total) [\%] & 26 & 35 & 14.2 & 24 & 10 & 16.2 & 14.1 & 22 \\
\hline water-sol. $\mathrm{K}$ out of total $\mathrm{K}$ [\%] & 69 & 48 & 86 & 55 & 74 & 30 & 31 & 21 \\
\hline water-sol. Ca out of total Ca [\%] & NA & NA & NA & NA & 42 & 29 & 30 & 31 \\
\hline aerosol fraction* $[\%]$ & 17 & & 36 & & 15 & & 25 & \\
\hline K-conversion [\%] & 36 & & 16 & & 28 & & 70 & \\
\hline
\end{tabular}

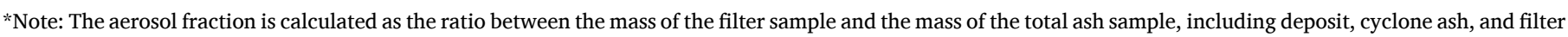
ash. 
Table 6

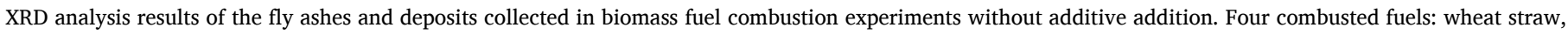
milled wood, SE-bark, and HTC-leaves, corresponding to Experiment Nos. 1, 2, 3, and 4 respectively.

\begin{tabular}{|c|c|c|c|c|c|c|c|c|c|}
\hline fuel & Sample: & $\mathrm{SiO}_{2}$ & $\mathrm{CaO}$ & $\mathrm{KCl}$ & $\mathrm{K}_{2} \mathrm{SO}_{4}$ & $\mathrm{KAlSiO}_{4}$ & $\mathrm{Ca}_{2} \mathrm{SiO}_{4}$ & $\mathrm{CaCO}_{3}$ & Ca-Al/Si spices \\
\hline \multirow[t]{4}{*}{ Wheat straw } & Filter aerosols & & & $\mathrm{x}$ & $\mathrm{x}$ & & & & \\
\hline & Cyclone ash & $\mathrm{x}$ & $\mathrm{x}$ & $\mathrm{x}$ & & & & & \\
\hline & Deposit top & $\mathrm{x}$ & & $\mathrm{x}$ & $\mathrm{x}$ & & & & \\
\hline & Deposit bottom $^{a}$ & & & $\mathrm{x}$ & $\mathrm{x}$ & & & & \\
\hline \multirow[t]{4}{*}{ Milled wood } & Filter aerosols & $\mathrm{x}$ & $\mathrm{x}$ & $\mathrm{x}$ & $\mathrm{x}$ & & & & $\mathrm{x}$ \\
\hline & Cyclone ash & $\mathrm{x}$ & $\mathrm{x}$ & & & & & $\mathrm{x}$ & $\mathrm{x}$ \\
\hline & Deposit top & $\mathrm{x}$ & $\mathrm{x}$ & & $\mathrm{x}$ & & $\mathrm{x}$ & & $\mathrm{x}$ \\
\hline & Deposit bottom & $\mathrm{x}$ & $\mathrm{x}$ & & $\mathrm{x}$ & & $\mathrm{x}$ & & $\mathrm{x}$ \\
\hline \multirow[t]{4}{*}{ SE-bark } & Filter aerosols & $\mathrm{x}$ & $\mathrm{x}$ & $\mathrm{x}$ & $\mathrm{x}$ & $\mathrm{x}$ & & & \\
\hline & Cyclone ash & $\mathrm{x}$ & $\mathrm{x}$ & & & $\mathrm{x}$ & $\mathrm{x}$ & & \\
\hline & Deposit top & $\mathrm{x}$ & $\mathrm{x}$ & & & & $\mathrm{x}$ & $\mathrm{x}$ & \\
\hline & Deposit bottom & $\mathrm{x}$ & $\mathrm{x}$ & & & & & & \\
\hline \multirow[t]{4}{*}{ HTC-leaves } & Filter aerosols & & $\mathrm{x}$ & $\mathrm{x}$ & & & & & \\
\hline & Cyclone ash & $\mathrm{x}$ & $\mathrm{x}$ & & & $\mathrm{x}$ & $\mathrm{x}$ & & \\
\hline & Deposit top & $\mathrm{x}$ & $\mathrm{x}$ & & & & $\mathrm{x}$ & & \\
\hline & Deposit bottom & $\mathrm{x}$ & $\mathrm{x}$ & & & & & & \\
\hline
\end{tabular}

Notes: a. The $\mathrm{KCl}$ peaks at the bottom of the deposit were much stronger than those atop the deposit.

Table 7

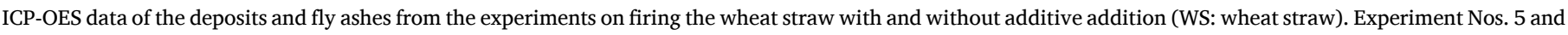
9 were conducted under the same conditions. K-conversion and K-capture values were calculated on the basis of fly ash samples (cyclone and filer sample).

\begin{tabular}{|c|c|c|c|c|c|c|c|c|c|c|c|c|}
\hline \multirow{3}{*}{$\begin{array}{l}\text { Experiment No. } \\
\text { Fuels }\end{array}$} & \multirow{2}{*}{\multicolumn{2}{|c|}{$\frac{1}{W S}$}} & \multirow{2}{*}{\multicolumn{2}{|c|}{$\frac{\mathbf{5}}{\text { WS }+3.13 \% \text { kaolin }}$}} & \multirow{2}{*}{\multicolumn{2}{|c|}{$\frac{6}{\mathrm{WS}+3.98 \% \text { CFA-A }}$}} & \multirow{2}{*}{\multicolumn{2}{|c|}{$\frac{7}{\text { WS }+5.15 \% \text { CFA-H }}$}} & \multirow{2}{*}{\multicolumn{2}{|c|}{$\frac{8}{\text { WS }+6.26 \% \text { kaolin }}$}} & \multirow{2}{*}{\multicolumn{2}{|c|}{$\frac{9}{\mathrm{WS}+3.13 \% \text { kaolin }}$}} \\
\hline & & & & & & & & & & & & \\
\hline & Fly ash & Dep. & Fly ash & Dep. & Fly ash & Dep. & Fly ash & Dep. & Fly ash & Dep. & Fly ash & Dep. \\
\hline K (water-soluble) [\%] & 8.5 & 3.9 & 3.5 & 2.5 & 5.2 & 2.2 & 3.9 & 2.2 & 1.7 & 0.8 & 5.6 & 2.5 \\
\hline K (total) [\%] & 12.4 & 8.2 & 12.1 & 6.8 & 11.3 & 6 & 10.7 & 5.9 & 11.2 & 5.6 & 15.4 & 6.7 \\
\hline Al (total) [\%] & 1.1 & 0.14 & 9 & 3 & 6.6 & 4.2 & 6.6 & 3.7 & 13.3 & 5.3 & 10.1 & 3.1 \\
\hline $\mathrm{Ca}$ (total) [\%] & 7.4 & 2.9 & 3.9 & 2.9 & 4.9 & 3.5 & 4.8 & 3.6 & 1.7 & 2.9 & 1.8 & 3 \\
\hline $\mathrm{Cl}$ (total) [\%] & 5.9 & 1.6 & 2.6 & 0.8 & 3.7 & 0.7 & 3.2 & 0.8 & 1.2 & $<0.5$ & 4.5 & 0.6 \\
\hline Si (total) [\%] & 26 & 35 & 24 & 34 & 24 & 33 & 25 & 32 & 25 & 33 & 24 & 30 \\
\hline water-sol. $\mathrm{K}$ out of total $\mathrm{K}$ [\%] & 69 & 48 & 29 & 37 & 46 & 37 & 36 & 37 & 15 & 15 & 36 & 37 \\
\hline aerosol fraction* [\%] & 17 & & 13 & & 13 & & 11 & & 10 & & 20 & \\
\hline K-conversion $[\%]$ & 36 & & 69 & & 52 & & 60 & & 83 & & 61 & \\
\hline K-capture [g K/g additive] & $\mathrm{NR}^{\mathrm{a}}$ & & 0.20 & & 0.12 & & 0.11 & & 0.12 & & 0.18 & \\
\hline
\end{tabular}

Note: ${ }^{\mathrm{a}} \mathrm{NR}$ : this filed is not related.

salt formation. The deposit has a very porous structure, and the outermost layer of the deposit is very loose, which can be removed by a simple rotation of the probe. The middle layer is beneath the outer layer; it is more compact, still mainly black, and is stickier, and physical force was required to remove it. This indicates a stronger sintering of the inner deposit layers. As sintering increases with temperature, this observation indicates that time has an effect as well, as the newer deposit is much looser and less sintered. Lastly, a white inner layer, much alike the white layer observed for wheat straw combustion without additive, had to be brushed off with force.

In Fig. 7 (B), which was obtained for the wheat straw combustion with coal fly ash addition, a similar structure is observed: a very loose main body with a white K-salt layer on the side of the deposit probe. The main body can be easily removed by simply turning the probe upside down. A notable difference, compared to the kaolin addition experiments, is that the white K-salt layer is thicker and wider.

The deposit with $6.26 \%$ kaolin addition (Fig. 7 (D)) is more grayish, and only a few white spots are seen on the outermost layer. This indicates that the double dosage of additive has a noticeable effect on the K-salt formation. In addition, the deposits are extremely loose and fragile. Even a slight vibration, for example, to extract the deposit probe from the chamber, resulted in a fall of the deposit. The experiment was repeated three times, and with careful operation, we obtained this undestroyed deposit. The entire deposit, except for the innermost layer, could be removed by simply turning the deposit probe upside down. The innermost layer still required brushing for its removal, but there was significantly less material that required removal. The deposit structure is generally similar to that in Experiment No. 5, wherein kaolin was added as an additive as well. However, in this case, the structure is much more porous and, as shown in Fig. 7 (D), the sections of the deposit fall off, creating visible holes in the structure. These areas are indicated by the green circles in Fig. 7 (D). These were hypothesized to have formed during the experiment, wherein the flue gas flow was only sufficient to remove parts of the deposit.

The deposits formed from milled wood combustion with additive addition are shown in Fig. 7. It is observed that with kaolin or coal fly ash addition, a distinct white layer is formed on both sides of the deposit probe and on the spots on the deposit body formed therein. A much less distinct white layer is observed in the milled wood combustion without additive addition, as seen in Fig. 5 (B). Additionally, the beige layer observed in the no additive experiment (Fig. 5 (B)) completely disappears, indicating a possible change in the salt formation in the process due to the additive. This is confirmed by the XRD analysis of the Deposit Bottom samples (Table 10). This shows that without additive addition, $\mathrm{Ca}-\mathrm{Si}$ minerals are formed in the inner deposit layer, whereas with additive addition, $\mathrm{CaCO}_{3}$ is formed in the inner layer and no traces of $\mathrm{Ca}-\mathrm{Si}$ minerals are detected.

Compared to the experiments without additive addition, the deposit buildup formed in the experiments with additives is less sintered. Additionally, a larger deposit buildup area is observed with the addition of additives. This possibly stems from the increased amount of total ash when additives are added. 

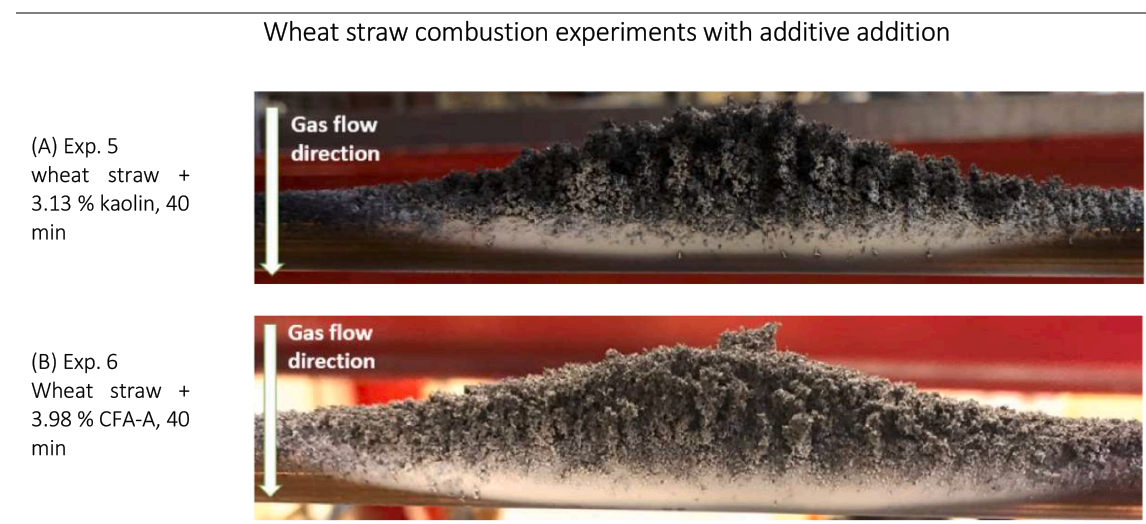

(C) Exp. 7

Wheat straw +

$5.15 \%$ CFA-H, 40

$\min$
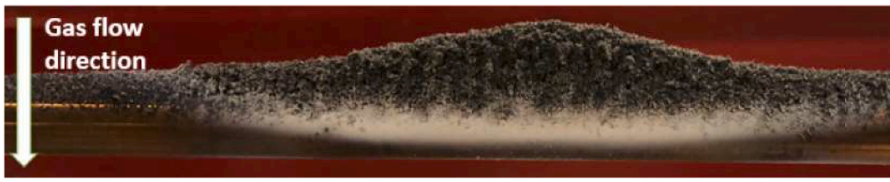

(D) Exp. 8

Wheat straw +

$6.26 \%$ kaolin, 30

$\min$

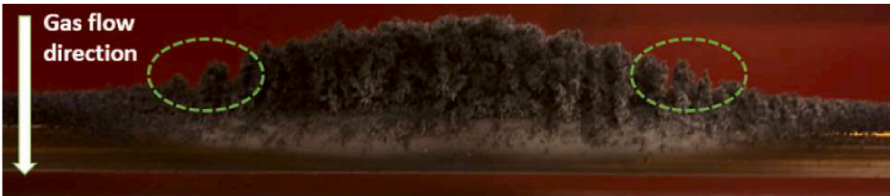

(E) Exp. 9

Wheat straw +

$3.13 \%$

Kaolin, $40 \mathrm{~min}$

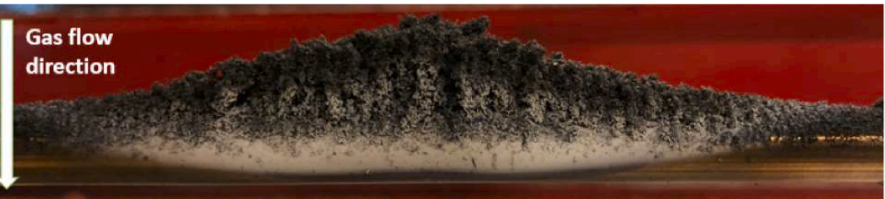

Milled wood combustion experiments with additive addition

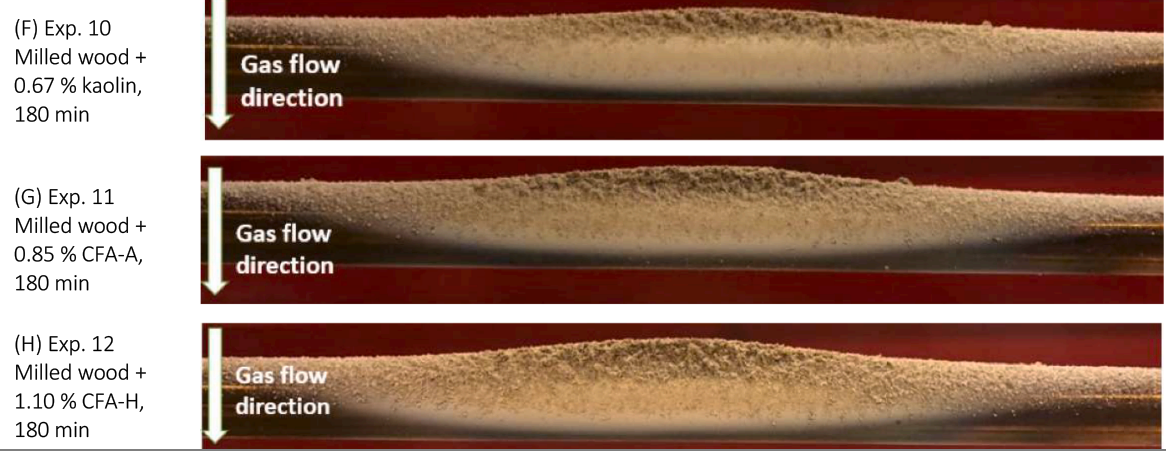

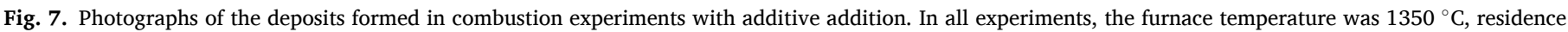
time was $2.0 \mathrm{~s}$, excess air ration $\lambda=1.3$, and deposit probe surface temperature was $600{ }^{\circ} \mathrm{C}$.

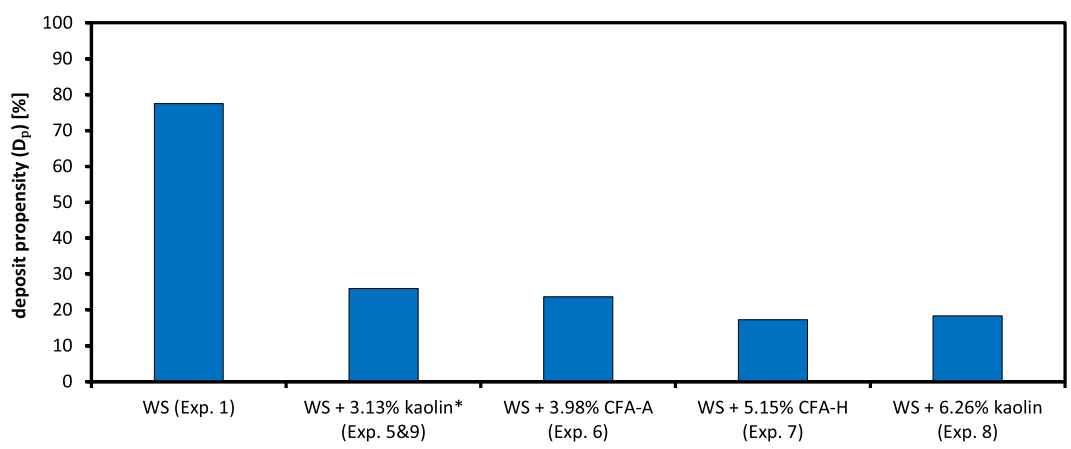

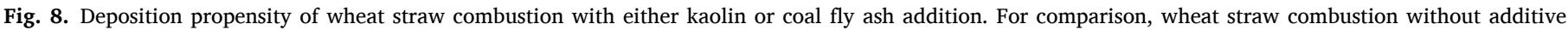
addition, is also shown (WS: wheat straw). *Note: the value of WS $+3.13 \%$ kaolin is the average of Experiment Nos. 5 and 9 , under the same conditions. 


\subsubsection{Deposition propensity with additive addition}

The influence of additive addition on deposit formation and fly ash properties was investigated in Experiment Nos. 5-12. Wheat straw and milled wood pellets were fired with additives in Experiment Nos. 5-9 and Nos. 10-12, respectively. In Experiment Nos. 5-7 and Nos. 9-12, the molar ratio of fuel-K/additive-Al in the reactants was maintained at 1.0. To study the influence of additive dosage, the dosage of kaolin was doubled in Experiment No. 8, achieving a molar ratio of fuel-K/additive$\mathrm{Al}$ as 0.5 in the feed.

The deposition propensities of wheat straw combustion with kaolin or coal fly ash addition (Experiment Nos. 5-9) are shown in Fig. 8. For comparison, the deposition propensity of wheat straw combustion without additive addition is included as well. A highly significant effect on the deposition propensity is observed in Fig. 8; for example, with 3.13 $\%$ kaolin addition (fuel-K/additive- $\mathrm{Al}=1.0$ ), the deposition propensity of wheat straw combustion decreases significantly to $26.0 \%$, compared to wheat straw combustion without additive addition, wherein a high deposition propensity of $77.5 \%$ is observed. Similar phenomena have been reported in previous publications $[13,26]$. Thus, the fixation of $\mathbf{K}$ by the additive causes a significant reduction in the deposit formation of straw. The use of $3.98 \%$ CFA-A leads to a similar reduction in the deposition propensity. With $5.15 \%$ CFA-H coal fly ash addition, a slightly lower deposition propensity is observed. At double kaolin dosage, the deposition propensity is similar to that of the $5.15 \% \mathrm{CFA}-\mathrm{H}$ experiment.

For the combustion of milled wood pellets with additives, all experiments were conducted with a fuel-K/additive-Al molar ratio of 1.0. Because of the much lower ash content of the milled wood pellets, the additive dosage in this series of experiments was significantly lower than that in wheat straw combustion. As seen in Fig. 9, the deposition propensity of the milled wood pellet combustion without additive addition is much lower than that of wheat straw. The addition of kaolin results in an insignificant decrease in the deposition propensity. Moreover, there is a small increase in the deposition propensity with the addition of two types of coal fly ash. This is because the deposition formation is mainly contributed by inertial impaction, and this mechanism is not obviously influenced by additive addition.

\subsubsection{Chemical characterization of deposits and fly ashes}

The deposits and fly ash samples collected from the experiments (with additives) were characterized by ICP-OES and XRD. The results are compared and discussed in this section.

4.3.3.1. Elemental composition based on ICP-OES analysis. The bulk elemental compositions of the fly ash and the deposits were analyzed by ICP-OES, and the results are listed in Table 7 . The fraction of watersoluble $\mathrm{K}$ and the concentration of $\mathrm{Cl}$ in the deposits in Experiment Nos. 5-9 (with additive addition) are significantly lower than those in Experiment No. 1 (without additive addition). This shows that additive

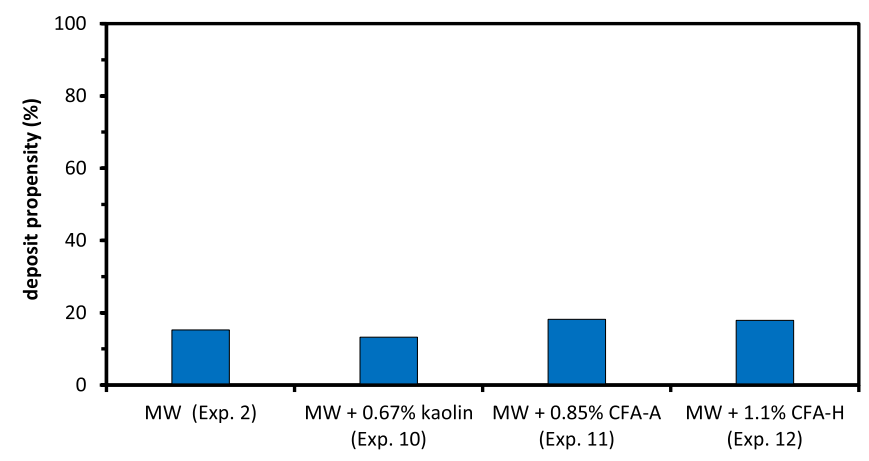

Fig. 9. Deposition propensity of milled wood pellet combustion with kaolin or coal fly ash addition. For comparison, milled wood pellet combustion without additive addition is also included (MW: milled wood). dosing has a significant impact on the fraction of water-soluble $\mathrm{K}$, both in the deposit and fly ash, and thereby the K-salt fraction in both deposits and fly ash decreases. The K-conversion into water-insoluble species in the fly ash increases from $36 \%$ in the straw-fired experiment to $52-83 \%$ in the additive experiments. The highest conversion of $83 \%$ is observed in Experiment No. 8 with the addition of $6.26 \%$ kaolin. Comparing the elemental compositions of the fly ash and deposits, it is inferred that the deposits have a lower K-, Al-, and Cl-content but a higher Si content than the fly ash. This indicates that the deposit formation process is dominated by the potassium silicate species.

The fly ash and deposit chemical compositions of the wood combustion experiments with additive addition are shown in Table 8 . Compared to the wheat straw results, a higher Ca content and a lower $\mathrm{Si}$ content are observed in all samples. The fly ash deposit samples are enriched in $\mathrm{Al}$ when additives used. The K-conversion into waterinsoluble species in the fly ash increases from $16 \%$ in the wood-fired experiment without additive addition to $49-63 \%$ in the additive experiments.

The K-conversions into water-insoluble species are similar for the two coal fly ashes and kaolin samples. The straw has a slightly higher Kconversion level than wood. Considering the aerosol formation data in Table 7 and Table 8, the fraction of aerosols out of total ash slightly decreases with kaolin/coal fly ash addition. However, this does not signify that the total emissions of aerosols decrease. Therefore, even if the additives fix certain alkali species in larger Si- and Al-rich particles to some extent, the additives contribute to aerosol formation as well.

4.3.3.2. Mineralogical study base on XRD analysis. The fly ash aerosols collected in the filter, large particles collected in the cyclone, and deposits collected on the deposit probe were analyzed by XRD. The deposit samples were separated into two parts on the basis of their locations. As shown in Fig. 10, the deposit is predominantly located on the upstream side of the probe. The top part of the deposit can usually be removed easily, and they are collected as the "Deposit Top." The smaller amount of sintered deposit beneath it usually has to be removed by brushing, and this part of the deposit is collected as "Deposit Bottom." The XRD results are summarized in Table 9 and Table 10.

The XRD results in Table 9 show that $\mathrm{KCl}$ and $\mathrm{K}_{2} \mathrm{SO}_{4}$ are the dominant species in all the filter samples from the wheat straw experiments (with and without additive addition), agreeing well with the observation that white salt samples are always formed during wheat straw experiments. The comparison of experiments without (Experiment No. 1) and with additive addition (Experiment Nos. 5-8) infers that the mineral species appearance has no significant change and no K-Al-Si compounds are detected with kaolin or coal fly ash addition, although the ICP-OES data indicate the formation of water-insoluble K-species. This is probably because $\mathrm{K}$ appears in some amorphous $\mathrm{K}$ water-insoluble species, which cannot be detected by XRD. A similar phenomenon is observed in the milled wood combustion experiments. In contrast to the wheat straw experiment samples, the milled wood samples have more $\mathrm{Ca}$-, $\mathrm{Mg}$-, and Si-rich minerals because the milled wood fuel is rich in these elements.

\subsection{Comparison of K-capture with K-salt or biomass combustion}

The K-conversion fraction and K-capture level by kaolin and coal fly ash under suspension-fired conditions (in the EFR) when firing real biomass were compared with those from our previous work in the same reactor [14-18], wherein K-salt was fed in the form of $\mathrm{KOH}$ and reacted with the solid additives. The objective of this comparison is to understand the difference between the K-capture reactions in real biomass combustion and using K-salt feeding. This is because most of the available K-capture studies use alkali salt injection instead of real biomass combustion. Therefore, this study provides a better guideline for using the available literature data for industrial K-capture. The K-capture level 
Table 8

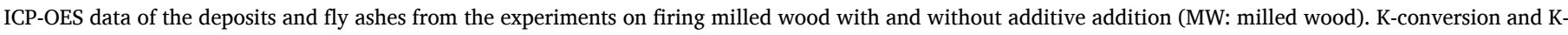
capture values were calculated on the basis of fly ash samples (cyclone and filer sample).

\begin{tabular}{|c|c|c|c|c|c|c|c|c|}
\hline \multirow{2}{*}{$\begin{array}{l}\text { Experiment No. } \\
\text { Fuels } \\
\end{array}$} & \multicolumn{2}{|l|}{2} & \multicolumn{2}{|l|}{10} & \multicolumn{2}{|l|}{11} & \multicolumn{2}{|l|}{12} \\
\hline & \multicolumn{2}{|c|}{ milled wood } & \multicolumn{2}{|c|}{ milled wood $+0.67 \%$ kaolin } & \multicolumn{2}{|c|}{ milled wood $+0.85 \%$ CFA-A } & \multicolumn{2}{|c|}{ milled wood $+1.1 \%$ CFA- } \\
\hline & Fly ash & Dep. & Fly ash & Dep. & Fly ash & Dep. & Fly ash & Dep. \\
\hline K (water-soluble) [\%] & 8.4 & 2.8 & 3.7 & 1.6 & 3.6 & 1.2 & 2.3 & 1.1 \\
\hline K (total) [\%] & 9.8 & 5.1 & 8.8 & 4.1 & 7.2 & 3.9 & 6.7 & 4.0 \\
\hline Al (total) [\%] & 1.9 & 2.2 & 8.1 & 5.3 & 5.8 & 7.1 & 6.1 & 6.4 \\
\hline $\mathrm{Ca}$ (total) [\%] & 21 & 15.3 & 17.3 & 17.3 & 21 & 21 & 17.6 & 17.6 \\
\hline $\mathrm{Cl}$ (total) [\%] & 1.6 & $<0.5$ & 1.1 & $<0.5$ & 0.7 & $<0.5$ & 0.7 & $<0.5$ \\
\hline Si (total) [\%] & 14.2 & 24 & 14.5 & 22 & 14.3 & 23 & 16.4 & 22 \\
\hline water-sol. $\mathrm{K}$ out of total $\mathrm{K}$ [\%] & 86 & 55 & 42 & 39 & 50 & 31 & 34 & 28 \\
\hline aerosol fraction* $[\%]$ & 36 & - & 22 & - & 22 & - & 16 & - \\
\hline K-conversion [\%] & 16 & & 55 & & 49 & & 63 & \\
\hline K-capture [g K/g additive] & NR & & 0.16 & & 0.11 & & 0.11 & \\
\hline
\end{tabular}

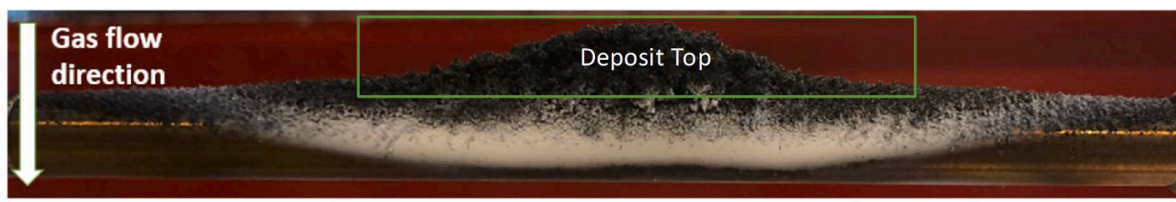

Fig. 10. Schematic of "Deposit Top" sample collected from the EFR experiments. The "Deposit Bottom" sample is beneath the "Deposit Top" sample.

Table 9

$\mathrm{XRD}$ results of deposits and fly ashes (filter and cyclone ashes) from the experiments on firing wheat straw (WS) with and without additive addition.

\begin{tabular}{|c|c|c|c|c|c|}
\hline & & $\mathrm{SiO}_{2}$ & $\mathrm{CaO}$ & $\mathrm{KCl}$ & $\mathrm{K}_{2} \mathrm{SO}_{4}$ \\
\hline \multirow[t]{4}{*}{ (B1) Exp. 1 WS } & Filter ash & & & $\mathrm{x}$ & $\mathrm{x}$ \\
\hline & Cyclone ash & $\mathrm{x}$ & $\mathrm{x}$ & $\mathrm{x}$ & \\
\hline & Deposit top & & & $\mathrm{x}$ & $\mathrm{x}$ \\
\hline & $\begin{array}{l}\text { Deposit } \\
\text { bottom }\end{array}$ & & & $\mathrm{x}$ & $\mathrm{x}$ \\
\hline (B2) Exp. 5. WS $+3.13 \%$ & Filter ash & & & $\mathrm{x}$ & $\mathrm{x}$ \\
\hline \multirow[t]{3}{*}{ kaolin } & Cyclone ash & $\mathrm{x}$ & $\mathrm{x}$ & $\mathrm{x}$ & \\
\hline & Deposit top & & & $\mathrm{x}$ & $\mathrm{x}$ \\
\hline & $\begin{array}{l}\text { Deposit } \\
\text { bottom }\end{array}$ & & & $\mathrm{x}$ & $\mathrm{x}$ \\
\hline (B3) Exp. 6 WS $+3.98 \%$ & Filter ash & & & $\mathrm{x}$ & $\mathrm{x}$ \\
\hline \multirow{3}{*}{ CFA-A } & Cyclone ash & $\mathrm{x}$ & $\mathrm{x}$ & $\mathrm{x}$ & \\
\hline & Deposit top & $\mathrm{x}$ & & $\mathrm{x}$ & $\mathrm{x}$ \\
\hline & $\begin{array}{l}\text { Deposit } \\
\text { bottom }\end{array}$ & $\mathrm{x}$ & & $\mathrm{x}$ & $\mathrm{x}$ \\
\hline (B4) Exp. 7 WS + 5.15\% & Filter ash & & & $\mathrm{x}$ & $\mathrm{x}$ \\
\hline \multirow[t]{3}{*}{ CFA-H } & Cyclone ash & $\mathrm{x}$ & $\mathrm{x}$ & $\mathrm{x}$ & \\
\hline & Deposit top & $\mathrm{x}$ & & $\mathrm{x}$ & $\mathrm{x}$ \\
\hline & $\begin{array}{l}\text { Deposit } \\
\text { bottom }\end{array}$ & $\mathrm{x}$ & & $\mathrm{x}$ & $\mathrm{x}$ \\
\hline (B5) Exp. 8 WS $+6.26 \%$ & Filter ash & & & $\mathrm{x}$ & $\mathrm{x}$ \\
\hline \multirow[t]{3}{*}{ kaolin } & Cyclone ash & $\mathrm{x}$ & $\mathrm{x}$ & $\mathrm{x}$ & \\
\hline & Deposit top & $\mathrm{x}$ & & $\mathrm{x}$ & $x$ \\
\hline & $\begin{array}{l}\text { Deposit } \\
\text { bottom }\end{array}$ & $\mathrm{x}$ & & $\mathrm{x}$ & $\mathrm{x}$ \\
\hline
\end{tabular}

and $\mathrm{K}$-conversion fraction as a function of the molar ratio of fuel-K/ additive- $\mathrm{Al}$ are compared in Figs. 11 and 12.

As shown in Fig. 11, with a molar fuel-K/additive-Al of 0.5, using kaolin, the K-capture level and K-conversion fraction are similar to those under K-salt reaction conditions. When the molar ratio of fuel-K/ additive-Al increases to 1.0, the K-capture level and K-conversion fraction under real biomass combustion conditions are slightly lower than those under K-salt reaction conditions. However, an opposite trend is observed for coal fly ash, as shown in Fig. 12, where a higher K-capture level and K-conversion fraction are observed when firing real biomass. This is probably because the reaction temperature is higher in the cases of biomass combustion. The furnace temperature was set to $1350{ }^{\circ} \mathrm{C}$, while the combustion of wood or straw may lead to even higher reaction temperatures. A higher temperature is favorable for coal fly ash but not for kaolin from the viewpoint of K-capture reaction. We believe that this is related to the transport of salt species within the additive particles. A high furnace temperature can enhance the transformation of kaolin to mullite, which is less reactive to K-salts than to kaolin or meta-kaolin. In comparison, mullite is the main active K-capture compound in coal fly ash; the higher temperature does not influence its reactivity but may induce melting of the coal fly ash particles, thereby promoting the diffusion of K-salt into fly ash particles. The mullite in the coal fly ash is present alongside other species that may act as fluxing agents that induce melting of the ash. In contrast, the relatively clean mullite in kaolin has a higher melting temperature, and therefore, the lower viscosity limits the salt diffusion.

In summary, under biomass suspension combustion conditions, similar or relatively lower K-capture levels and K-conversion fractions were observed for kaolin, but for coal fly ash, they were higher under biomass combustion conditions. The fuel combustion condition is clearly more complex than the test with the selected salts and additives. For example, in the case of fuel combustion, potassium may appear as different species, such as $\mathrm{KCl}, \mathrm{KOH}$, and $\mathrm{K}_{2} \mathrm{SO}_{4}$. However, the similar trends observed for the salt reaction experiments and combustion experiments confirmed that salt experiments provide relevant data for boiler conditions.

\section{Conclusions}

The deposit formation behavior and fly ash properties of four different dust fuels were experimentally studied using the DTU EFR. The impact of additive addition was also investigated by performing wheat straw and wood combustion experiments with additives (kaolin and two coal fly ashes). The ash and deposit samples were analyzed by XRD and ICP-OES. The experimental data were also compared to those of our previous experiments, in which pure K-salt reacted with solid additives.

The results showed that the $\mathrm{K}$ - and Cl-rich wheat straw is the most problematic fuel, leading to the highest deposit formation propensity (86\%), while HTC-leaves, SE-bark, and milled wood had significantly lower deposition propensity. The elemental composition of ash from the fuels strongly influenced the deposit formation process. A fuel rich in both $\mathrm{Si}$ and Al relative to $\mathrm{K}$ had the potential to bind $\mathrm{K}$ to the species with high melting temperatures, thus leading to less formation of hard 
Table 10

XRD results of deposits and fly ashes (filter and cyclone ashes) from the experiments on firing milled wood (MW) with and without additive addition.

\begin{tabular}{|c|c|c|c|c|c|c|c|c|c|c|}
\hline & & $\mathrm{SiO}_{2}$ & $\mathrm{CaO}$ & $\mathrm{KCl}$ & $\mathrm{K}_{2} \mathrm{SO}_{4}$ & $\mathrm{Ca}_{2} \mathrm{SiO}_{4}$ & $(\mathrm{CaO})_{12}\left(\mathrm{Al}_{2} \mathrm{O}_{3}\right)_{7}$ & $\mathrm{Ca}_{3} \mathrm{Mg}\left(\mathrm{SiO}_{4}\right)_{2}$ & $\mathrm{Ca}_{2} \mathrm{SiO}_{4} \times\left(\mathrm{H}_{2} \mathrm{O}\right)$ & $\mathrm{CaCO}_{3}$ \\
\hline \multirow[t]{4}{*}{ (B8)Exp. 2 MW } & Cyclone ash & $\mathrm{x}$ & $\mathrm{x}$ & & & & $\mathrm{x}$ & $\mathrm{x}$ & & $\mathrm{x}$ \\
\hline & Filter ash & $\mathrm{x}$ & $\mathrm{x}$ & $\mathrm{x}$ & $\mathrm{x}$ & & & $\mathrm{x}$ & & \\
\hline & Deposit top & $\mathrm{x}$ & $\mathrm{x}$ & & $\mathrm{x}$ & $\mathrm{x}$ & & & $\mathrm{x}$ & \\
\hline & Deposit bottom & $\mathrm{x}$ & $\mathrm{x}$ & & $\mathrm{x}$ & $\mathrm{x}$ & & & $\mathrm{x}$ & \\
\hline \multirow[t]{4}{*}{ (B9) Exp. $10 \mathrm{MW}+0.67 \%$ kaolin } & Cyclone ash & $\mathrm{x}$ & $\mathrm{x}$ & & & & $\mathrm{x}$ & $\mathrm{x}$ & & $\mathrm{x}$ \\
\hline & Filter ash & $\mathrm{x}$ & & $\mathrm{x}$ & $\mathrm{x}$ & & & $\mathrm{x}$ & & \\
\hline & Deposit top & $\mathrm{x}$ & $\mathrm{x}$ & & $\mathrm{x}$ & & & & & $\mathrm{x}$ \\
\hline & Deposit bottom & $\mathrm{x}$ & $\mathrm{x}$ & & $\mathrm{x}$ & & & & & $\mathrm{x}$ \\
\hline \multirow[t]{4}{*}{ (B10) Exp. 11 MW + CFA-A } & Cyclone ash & $\mathrm{x}$ & $\mathrm{x}$ & & & & $\mathrm{x}$ & $\mathrm{x}$ & & $\mathrm{x}$ \\
\hline & Filter ash & $\mathrm{x}$ & $\mathrm{x}$ & $\mathrm{x}$ & $\mathrm{x}$ & & & & & \\
\hline & Deposit top & $\mathrm{x}$ & $\mathrm{x}$ & & & & & & & $\mathrm{x}$ \\
\hline & Deposit bottom & $\mathrm{x}$ & $\mathrm{x}$ & & $\mathrm{x}$ & & & & & $\mathrm{x}$ \\
\hline \multirow[t]{4}{*}{ (B11) Exp. $12 \mathrm{MW}+$ CFA-H } & Cyclone ash & $\mathrm{x}$ & $\mathrm{x}$ & & & & $\mathrm{x}$ & $\mathrm{x}$ & & $\mathrm{x}$ \\
\hline & Filter ash & $\mathrm{x}$ & $\mathrm{x}$ & $\mathrm{x}$ & $\mathrm{x}$ & & & & & \\
\hline & Deposit top & $\mathrm{x}$ & $\mathrm{x}$ & & & & & & & $\mathrm{x}$ \\
\hline & Deposit bottom & $\mathrm{x}$ & $\mathrm{x}$ & & $\mathrm{x}$ & & & & & $\mathrm{x}$ \\
\hline
\end{tabular}

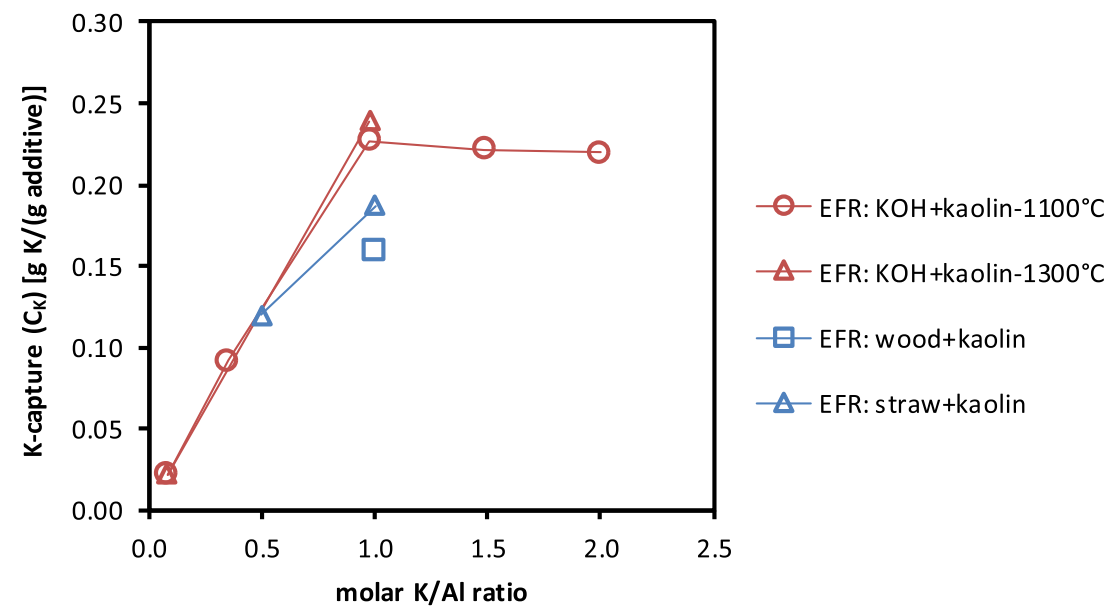

(A) K-capture level by kaolin

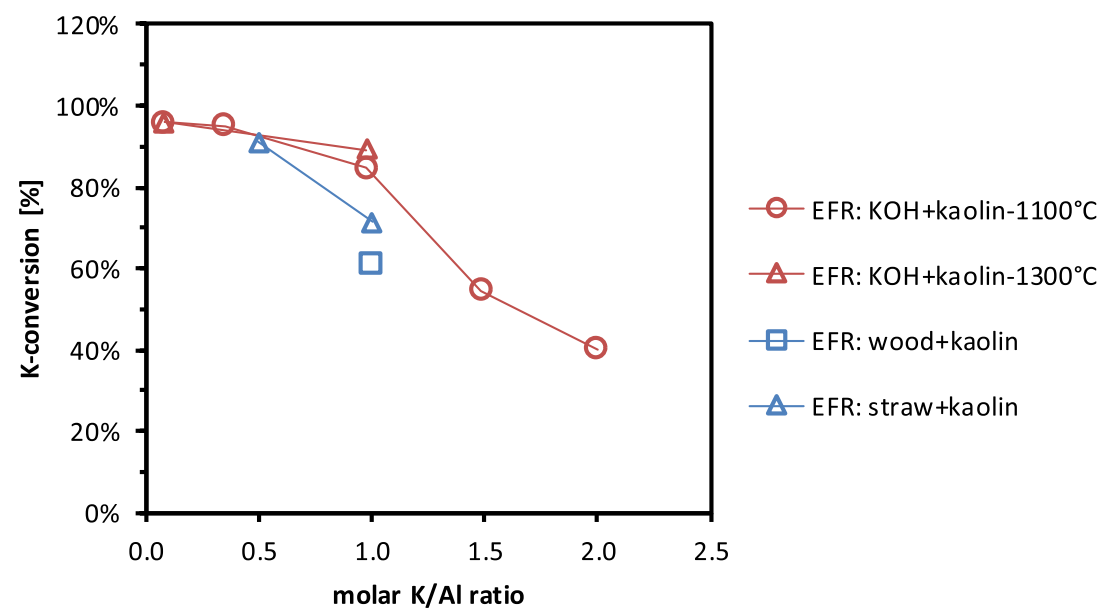

Fig. 11. Comparison of K-capture level and K-conversion with kaolin addition in the EFR with K-salt [15] or real biomass combustion.

deposits. Analysis of the deposit sample compositions showed that salt condensation played a smaller role than potassium silicate deposition when a high deposit probe temperature of $600{ }^{\circ} \mathrm{C}$ was applied.

The results for wheat straw and wood combustion with additive addition showed that with a kaolin dosage of $3.13 \%$ (feed fuel K/additive-Al $=1.0$ ), the deposition propensity of wheat straw sharply decreased from $86 \%$ to $29 \%$. Similar effects were observed for the addition of two types of coal fly ash. The fraction of $\mathrm{K}$ bound as a waterinsoluble species increased from $36 \%$ to 52-69 \% upon additive addition (feed fuel-K/additive-Al $=1.0$ ). Upon doubling the kaolin dosage to $6.26 \%$, the water-insoluble $\mathrm{K}$ content in the fly ash increased to $83 \%$. A similar trend was observed for wood-firing, i.e., a strong increase in $\mathrm{K}$ binding to $\mathrm{K}$-aluminosilicates upon adding the additives but with no change in the deposition propensity.

A comparison of the experimental results from this work to those of a study on pure $\mathrm{KOH}$-salt reaction with additives (no combustion in the reactor) showed that the K-capture level of kaolin in the case of biomass combustion was slightly lower than that under the K-salt reaction 


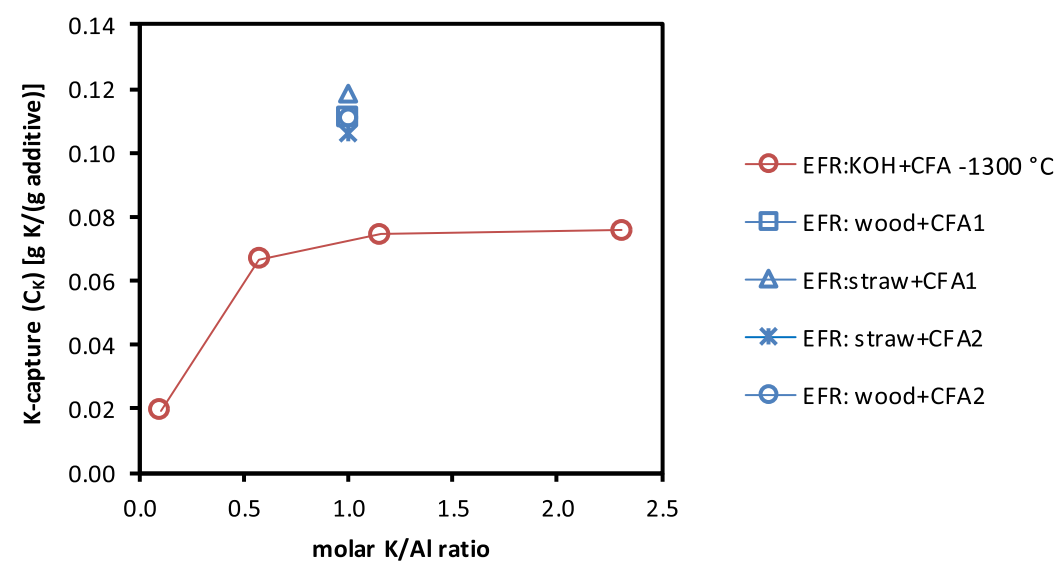

(A) K-capture level by coal fly ash

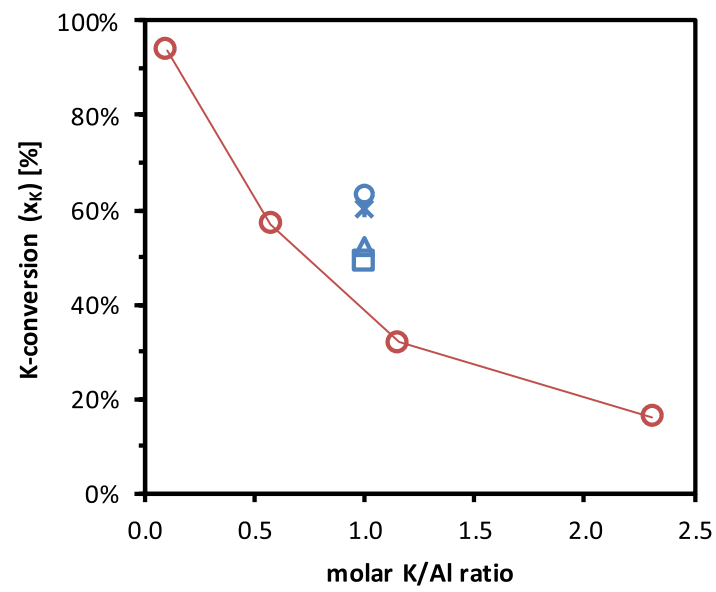

- - EFR:KOH+CFA $-1300^{\circ} \mathrm{C}$

曰-EFR: wood+CFA1

$\triangle$ EFR:straw+CFA1

$\rightarrow$ EFR: straw+CFA2

- - EFR: wood+CFA2

Fig. 12. Comparison of K-capture level and K-conversion with kaolin addition in the EFR with K-salt [17] or real biomass combustion.

conditions. However, in the case of coal fly ash, the K-capture level was higher when firing real biomass. The probable mechanism behind this is: a higher reaction temperature (in the case of biomass combustion) enhances the melting of the coal fly ash, thereby increasing the diffusion of the salt species in the coal fly ash.

\section{CRediT authorship contribution statement}

Guoliang Wang: Validation, Resources, Formal analysis, Writing review \& editing, Supervision. Jesper Naimi Funch Poulsen: Investigation, Writing - original draft, Formal analysis. Samira Naimi Funch Poulsen: Investigation, Writing - original draft, Formal analysis. Peter Arendt Jensen: Conceptualization, Funding acquisition, Supervision, Methodology. Flemming Jappe Frandsen: Conceptualization, Supervision, Funding acquisition, Methodology.

\section{Declaration of competing interest}

The authors declare that they have no known competing financial interests or personal relationships that could have influenced the work reported in this paper.

\section{Acknowledgements}

This work was supported by the European Union's Horizon 2020 Research and Innovation Program (EU Grant Agreement 727616). Research activities were conducted within the framework of the BIOFFICIENCY project.

\section{References}

[1] Ash FFJ, Formation,. Deposition and Corrosion When Utilizing Straw for Heat and Power Production. Technical University of Denmark; 2011.

[2] Zheng Y, Jensen AD, Johnsson JE. Laboratory investigation of selective catalytic reduction catalysts: Deactivation by potassium compounds and catalyst regeneration. Ind Eng Chem Res 2004;43:941-7. https://doi.org/10.1021/ ie030404a.

[3] Zheng Y, Jensen AD, Johnsson JE. Deactivation of V2O5-WO3-TiO2 SCR catalyst at a biomass-fired combined heat and power plant. Appl Catal B 2005;60(3-4): 253-64. https://doi.org/10.1016/j.apcatb.2005.03.010.

[4] Wu H, Wang G, Jensen PA, Frandsen FJ, Glarborg P. Reactive additives for alkali capture in biomass combustion. 27th Int. Conf. Impact Fuel Qual Power Prod Environ, Lake Louise, Canada: 2018.

[5] Damoe AJ, Wu H, Frandsen FJ, Glarborg P, Sander Bo. Impact of coal fly ash addition on combustion aerosols (PM2.5) from full-scale suspension-firing of pulverized wood. Energy Fuels 2014;28(5):3217-23. https://doi.org/10.1021/ ef5003815.

[6] Wang L, Hustad JE, Skreiberg Ø, Skjevrak G, Grønli M. A critical review on additives to reduce ash related operation problems in biomass combustion applications. Energy Procedia 2012;20:20-9. https://doi.org/10.1016/j. egypro.2012.03.004.

[7] Turn SQ, Kinoshita CM, Ishimura DM, Zhou J, Hiraki T, Mastani SM. A review of sorbent materials for fixed bed alkali getter systems in biomass gasifier combined cycle power generation applications. J Inst Energy n.d.;71:163-77.

[8] Niu Y, Tan H, Hui S. Ash-related issues during biomass combustion: Alkali-induced slagging, silicate melt-induced slagging (ash fusion), agglomeration, corrosion, ash utilization, and related countermeasures. Prog Energy Combust Sci 2016;52:1-61. https://doi.org/10.1016/j.pecs.2015.09.003.

[9] Woolcock PJ, Brown RC. A review of cleaning technologies for biomass-derived syngas. Biomass Bioenergy 2013;52:54-84. https://doi.org/10.1016/j. biombioe.2013.02. 036.

[10] Zheng Y, Jensen PA, Jensen AD. A kinetic study of gaseous potassium capture by coal minerals in a high temperature fixed-bed reactor. Fuel 2008;87(15-16): 3304-12. https://doi.org/10.1016/j.fuel.2008.05.003. 
[11] Uberoi M, Punjak WA, Shadman F. The kinetics and mechanism of alkali removal from flue gases by solid sorbents. Prog Energy Combust Sci 1990;16(4):205-11. https://doi.org/10.1016/0360-1285(90)90029-3.

[12] Tran K-Q, Iisa K, Steenari B-M, Lindqvist O. A kinetic study of gaseous alkali capture by kaolin in the fixed bed reactor equipped with an alkali detector. Fuel 2005;84(2-3):169-75. https://doi.org/10.1016/j.fuel.2004.08.019.

[13] Wu H, Glarborg P, Frandsen FJ, Dam-Johansen K, Jensen PA. Dust-firing of straw and additives: Ash chemistry and deposition behavior. Energy Fuels 2011;25(7): 2862-73. https://doi.org/10.1021/ef200452d.

[14] Wang G. Potassium Capture by Kaolin and Coal Fly Ash. Technical University of Denmark; 2018.

[15] Wang G, Jensen PA, Wu H, Frandsen FJ, Sander B, Glarborg P. Potassium capture by kaolin, Part 1: KOH. Energy Fuels 2018;32:1851-62. https://doi.org/10.1021/ acs. energyfuels.7b03645.

[16] Wang G, Jensen PA, Wu H, Frandsen FJ, Sander Bo, Glarborg P. Potassium capture by kaolin, Part 2: $\mathrm{K}_{2} \mathrm{CO}_{3}, \mathrm{KCl}$ and $\mathrm{K}_{2} \mathrm{SO}_{4}$. Energy Fuels 2018;32(3):3566-78. https://doi.org/10.1021/acs.energyfuels.7b04055.

[17] Wang G, Jensen PA, Wu H, Frandsen FJ, Laxminarayan Y, Sander Bo, et al. KOH capture by coal fly ash. Fuel 2019;242:828-36. https://doi.org/10.1016/j. fuel.2018.12.088.

[18] Wang G, Jensen PA, Wu H, Frandsen FJ, Laxminarayan Y, Sander B, et al. Potassium capture by coal fly ash: $\mathrm{K}_{2} \mathrm{CO}_{3}, \mathrm{KCl}$ and $\mathrm{K}_{2} \mathrm{SO}_{4}$. Fuel Processing Technology 2019;194. https://doi.org/10.1016/j.fuproc.2019.05.038:106115.
[19] Wu H, Bashir MS, Jensen PA, Sander B, Glarborg P. Impact of coal fly ash addition on ash transformation and deposition in a full-scale wood suspension-firing boiler. Fuel 2013;113:632-43. https://doi.org/10.1016/j.fuel.2013.06.018.

[20] Damoe AJ, Jensen PA, Frandsen FJ, Wu H, Glarborg P. Fly ash formation during suspension firing of biomass: Effects of residence time and fuel type. Energy Fuels 2017;31(1):555-70. https://doi.org/10.1021/acs.energyfuels.6b02051.

[21] Hansen L, Magiri-Skouloudi D, Braimakis K, Dr-Ing Sotirios Karellas D-I, Sebastian Fendt D-I, de Riese T, et al. et al The Biofficiency Project Part 2: A Blueprint Design for the Next Generation. of Biomass-Fired Cogeneration Plants; 2020.

[22] Niemelä NP, Nowak Delgado R, de Riese T, Tolvanen H, Fendt S, Spliethoff H, et al. Fuel-specific devolatilization parameters for detailed comparison of pulverized biomass fuels. Fuel 2021;286. https://doi.org/10.1016/j.fuel.2020.119309: 119309.

[23] Laxminarayan Y, Jensen PA, Wu H, Frandsen FJ, Sander Bo, Glarborg P. Biomass fly ash deposition in an entrained flow reactor. Proc Combust Inst 2019;37(3): 2689-96. https://doi.org/10.1016/j.proci.2018.06.039.

[24] Zheng Y, Jensen PA, Jensen AD, Sander Bo, Junker H. Ash transformation during co-firing coal and straw. Fuel 2007;86(7-8):1008-20. https://doi.org/10.1016/j. fuel.2006.10.008.

[25] Zhou H, Jensen PA, Frandsen FJ. Dynamic mechanistic model of superheater deposit growth and shedding in a biomass fired grate boiler. Fuel 2007;86(10-11): 1519-33.

[26] Formation LY. Sintering and Removal of Biomass Ash Deposits. Technical University of Denmark. 2018. https://doi.org/10.1108/13598540510624205. 